\title{
Hepatocellular carcinoma: current trends in worldwide epidemiology, risk factors, diagnosis, and therapeutics
}

This article was published in the following Dove Press journal:

Hepatic Medicine: Evidence and Research

7 May 2012

Number of times this article has been viewed

\author{
Renumathy Dhanasekaran \\ Alpna Limaye \\ Roniel Cabrera \\ Division of Gastroenterology, \\ Hepatology, and Nutrition, \\ Department of Medicine, University \\ of Florida, Gainesville, FL, USA
}

\begin{abstract}
Hepatocellular carcinoma (HCC) is a common malignancy in developing countries and its incidence is on the rise in the developing world. The epidemiology of this cancer is unique since its risk factors, including hepatitis $\mathrm{C}$ and $\mathrm{B}$, have been clearly established. The current trends in the shifting incidence of $\mathrm{HCC}$ in different regions of the world can be explained partly by the changing prevalence of hepatitis. Early detection offers the only hope for curative treatment for patients with HCC, hence effective screening strategies for high-risk patients is of utmost importance. Liver transplantation and surgical resection remains the cornerstone of curative treatment. But major advances in locoregional therapies and molecular-targeted therapies for the treatment of advanced HCC have occurred recently. In this review, current trends in the worldwide epidemiology, surveillance, diagnosis, standard treatments, and the emerging therapies for HCC are discussed.
\end{abstract}

Keywords: liver cancer, sorafenib, hepatitis C, TACE

\section{Introduction}

Hepatocellular carcinoma (HCC) is one of the leading causes of cancer-related deaths worldwide. More than 700,000 new cases are diagnosed each year throughout the world and also unfortunately more than 600,000 deaths are attributed to HCC each year. ${ }^{1}$ Although the majority of the cases occur in Asia and Africa, the incidence has also been rising in the developed world. In the United States, the incidence has tripled over the last three decades with over 20,000 cases estimated to be diagnosed in $2011 .^{1}$ The geographical variation in the incidence of HCC is explained by disparity in the prevalence of the major risk factors such as hepatitis $\mathrm{C}$ virus (HCV) and hepatitis $\mathrm{B}$ virus (HBV) infection. In contrast to most malignancies, the predisposing conditions and major risk factors have been clearly defined for HCC. By recognizing the risk factors for HCC, high-risk groups can be identified and followed with screening strategies. Following high-risk patients with screening and surveillance has the real potential to detect HCC early and improve patient outcomes. When HCC is detected earlier, patients are candidates to receive curative treatments such as liver transplantation (LT), surgical resection, or ablation. In recent years, there have also been some major advances in the treatment of advanced HCC.

\section{Epidemiology}

Although $\mathrm{HCC}$ is the most common primary hepatic malignancy worldwide, ${ }^{1}$ there are striking variations in its incidence in various parts of the world, with the major burden of disease falling on the developing world. ${ }^{2}$ As per the GLOBOCAN report, 746,300 
new cases of HCC were diagnosed worldwide in 2008 and HCC-related deaths in that year were reported to be 695,900 (Figure 1). ${ }^{2}$ The high incidence to mortality ratio of 1.07 for HCC makes it the third most common cause of cancer-related deaths worldwide. The vast majority of this cancer burden was concentrated in the developing world which bore $84 \%$ of the total worldwide incidence and $83 \%$ of the total deaths. This distribution closely follows the global distribution of $\mathrm{HBV}$ and $\mathrm{HCV}$ infection, with the highest rates of $\mathrm{HCC}$ seen in those regions where these infections are endemic. ${ }^{3,4}$ Overall, HCC displays a male predominance, occurring two to four times more often in males than in females. ${ }^{5}$

There are some interesting trends in the global incidence of HCC. The cancer incidence in Asian countries like China and Korea has been shown to be on the decline in population-based studies. ${ }^{6}$ This recent decline is owed to increased vaccination against hepatitis B and preventive measures taken against aflatoxin. ${ }^{7}$ In contrast to the decreasing rates in Asian countries, the developing world has actually been experiencing an acceleration of HCC incidence, especially in the United States and Japan (Figure 2). ${ }^{8-11}$ The increase has been mainly attributed to the large number of young adults who acquired HCV infection through intravenous drug use and blood transfusions between the 1960s and 1980s. Further, the rising epidemic of obesity, diabetes, and nonalcoholic steatohepatitis (NASH) are also believed to contribute to the increase in HCC. ${ }^{12}$ However, the overriding risk factor in $80 \%-90 \%$ of HCC cases regardless of etiology is the presence of the preneoplastic cirrhotic liver. ${ }^{13,14}$ Based on current predictions, the incidence of HCC in the United States is projected to continue to increase over the next two to three decades.

\section{Risk factors Hepatitis B (HBV)}

More than half of the world's HCC burden has been attributed to HBV infection. ${ }^{15}$ The International Agency for Research on Cancer in 1994 analyzed multiple cohort and case-control studies and reported that there was sufficient evidence in humans for the carcinogenicity of chronic HBV infection. ${ }^{16}$ The relative risk of HCC among people infected with HBV ranges from five to 49 in case-control studies and from seven to 98 in cohort studies. ${ }^{17}$ The etiopathogenesis of HBV-related HCC is complex and multiple pathways of carcinogenesis have been proposed. The process involves HBV causing chronic hepatic injury with cirrhosis and hepatocyte regeneration leading to accumulation of oncogenic mutations and also HBV DNA integration in the host genome causing transactivation of oncogenes of the host. ${ }^{18,19}$ While HBV can cause HCC in the absence of cirrhosis due to its ability to integrate into the host genome, the majority of the HBVrelated cases occur in the background of cirrhosis.

The risk of HCC in patients with active chronic HBV infections is well established. ${ }^{20-22}$ But a recent study also showed that carriers of inactive chronic HBV are at risk for HCC and liver-related deaths. ${ }^{23}$ In this study with a cohort of

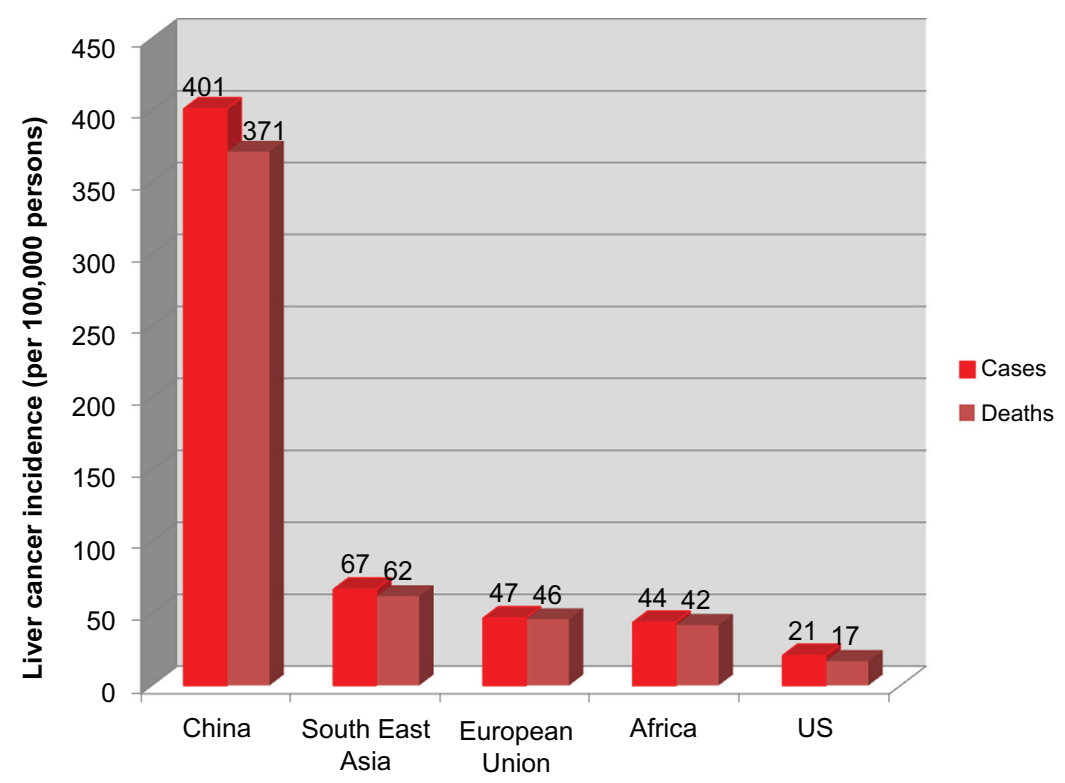

Figure I Age-standardized incidence rates of liver cancer (per 100,000 persons) in different regions of the world in 2008 based on International Agency for Research on Cancer GLOBOCAN 2008 report.

Note: Copyright $@$ 2010. Adapted with permission from John Wiley and Sons. Ferlay J, Shin HR, Bray F, Forman D, Mathers C, Parkin DM. Estimates of worldwide burden of cancer in 2008: GLOBOCAN 2008. Int J Cancer. 2010;127(I2):2893-2917. ${ }^{2}$

Abbreviation: US, United States. 


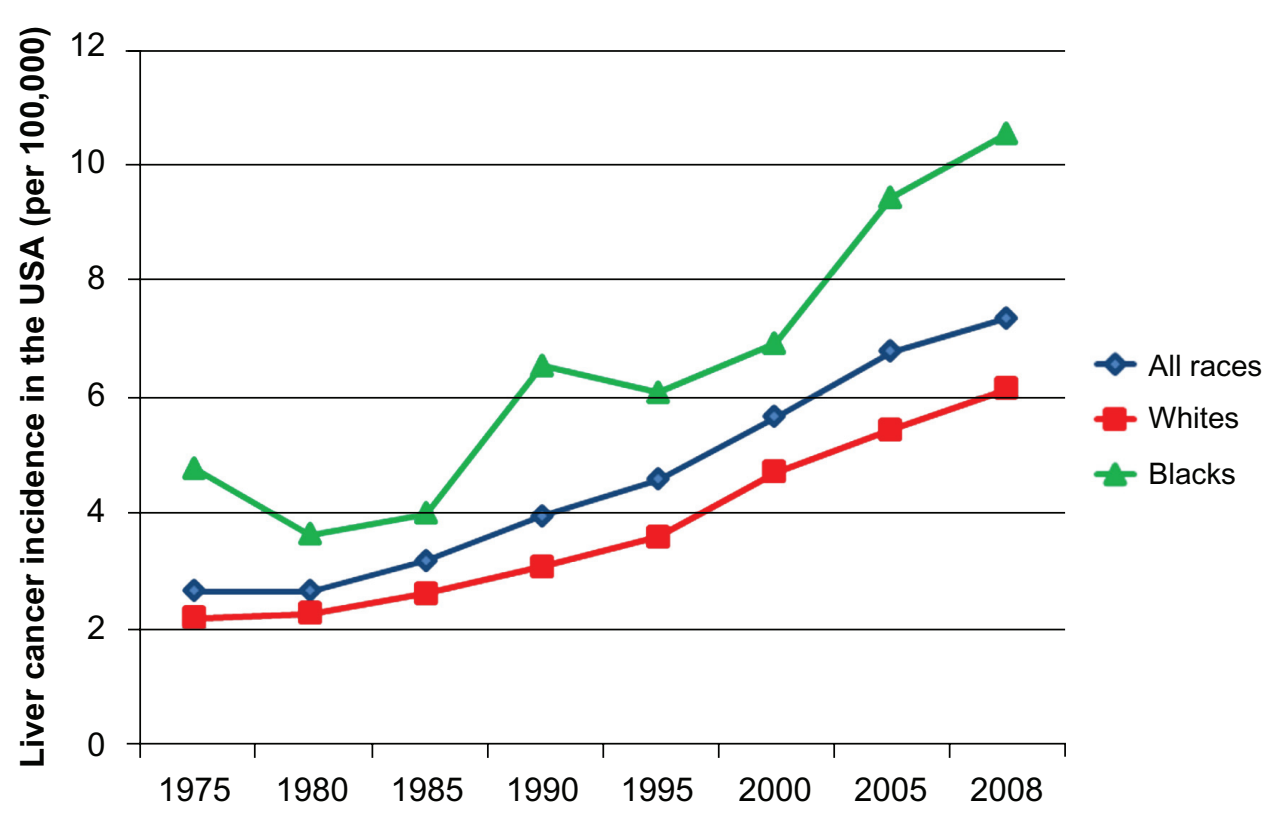

Figure 2 Age-adjusted incidence rates of liver cancer (per 100,000) in the United States based on the Surveillance, Epidemiology, and End Result database from 1975-2008.'

around 20,000 patients, the hazard ratios were 4.6 for carriers of inactive HBV to develop HCC and 2.1 for liver-related deaths. Among patients with chronic HBV, there are additional risk factors that further increase the risk of HCC. ${ }^{24,25}$ Recently a nomogram has been introduced for the calculation of the risk of developing HCC based on risk factors such as: male gender, older age, family history of HCC, use of alcohol or tobacco, serum alanine aminotransferase level, coinfection with $\mathrm{HCV}$, human immunodeficiency virus or hepatitis delta virus, persistent presence of hepatitis $B$ e antigen, high serum levels of HBV DNA, HBV genotype $\mathrm{C}$, and presence of cirrhosis. ${ }^{26}$ These tools can be helpful for the clinician while counseling patients regarding preventive measures and potential strategies to decrease risk for HCC.

\section{Hepatitis C (HCV)}

The increase in the incidence of HCC in developed countries is closely linked to the epidemic of chronic HCV. While chronic HCV accounts for only around a third of HCC cases in developing countries, most of the HCC in developed countries is related to chronic HCV. For example, in Japan $\mathrm{HCV}$ accounts for $80 \%-90 \%$ of $\mathrm{HCC}$ cases, while in Italy and the United States it accounts for $40 \%-60 \%$ of HCC cases. ${ }^{27,28}$ Fortunately, the annual incidence of acute acquisition of HCV has been steadily declining in the United States since the early 1990s (Figure 3). ${ }^{29,30}$ The estimated risk of developing HCC in patients with chronic HCV has been reported as a wide range of odds ratio from 1.3 to $134,{ }^{16}$ and a meta-analysis of 32 studies reported the risk to be increased 17 -fold. ${ }^{31}$

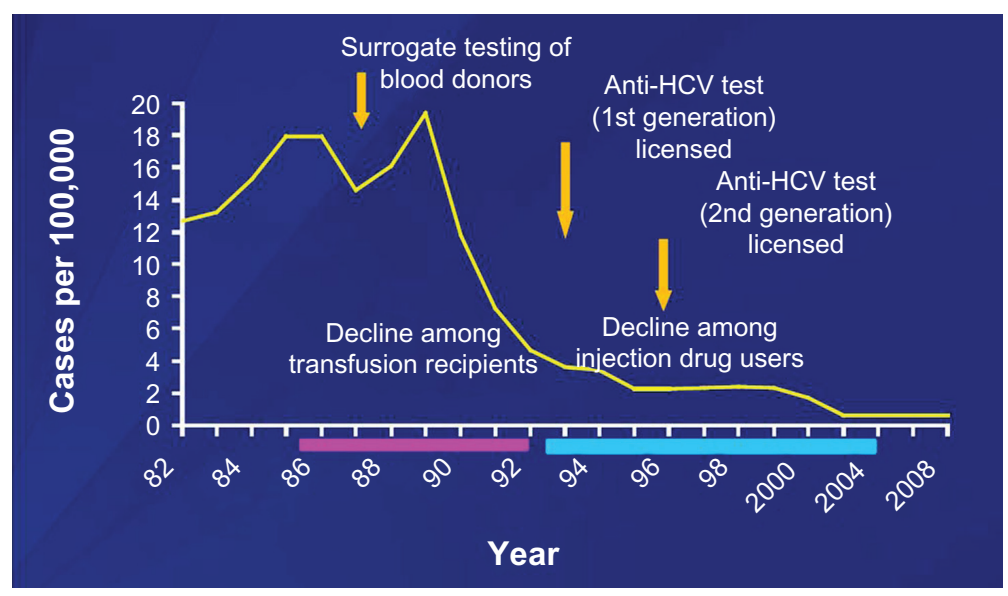

Figure 3 Estimate of total new infections of hepatitis C in the United States. Based on the Centers for Disease Prevention and Control report from I982-2008. ${ }^{30}$ Abbreviation: $\mathrm{HCV}$, hepatitis $\mathrm{C}$ virus. 
The major risk factor for $\mathrm{HCC}$ in patients with chronic $\mathrm{HCV}$ is advanced hepatic fibrosis or cirrhosis. ${ }^{32}$ Unlike HBV, $\mathrm{HCV}$ is a ribonucleic acid virus and hence cannot integrate into the host genome. Similar to HBV, the carcinogenesis of HCV-associated HCC is thought to be a multistep process involving upregulation of inflammatory cytokines and induction of oxidative stress from chronic hepatitis, fibrosis, liver regeneration, and, ultimately, the development of cirrhosis. ${ }^{33}$ These steps are likely shared by the risk factors that transform the liver parenchyma into the fibrotic nodules characteristic of cirrhosis, which sets the stage for dysplastic nodules and epigenetic and genetic changes resulting in the development of HCC. A number of risk factors can have a synergistic effect on the risk of $\mathrm{HCC}$ in patients with chronic $\mathrm{HCV}$ when present in combination. The association of HCV with the following risk factors has been shown to further increase the chances of developing HCC: alcohol use, coinfection with HBV or human immunodeficiency virus, diabetes mellitus, older age, African American race, thrombocytopenia, elevated alkaline phosphatase, esophageal varices, and smoking. ${ }^{33-36}$

\section{Nonalcoholic fatty liver disease (NAFLD)}

NAFLD is being diagnosed with increasing frequency in the Western countries as a manifestation of the metabolic syndrome - obesity and diabetes mellitus type 2 . The key process in NAFLD that predisposes patients to HCC is the development of NASH. The diagnosis of NASH relies on a biopsy with a histopathology showing features of steatosis, hepatocellular injury (ballooning, Mallory bodies), and fibrosis. ${ }^{37}$ The presence of NASH places patients at risk for progressive fibrosis and subsequent cirrhosis. The pathophysiology of hepatic carcinogenesis in patients with NAFLD-NASH has not been completely elucidated. ${ }^{38}$ But initial investigations suggest that excess fatty acid supply and hepatocellular steatosis elicit increased fatty acid oxidation with consecutively enhanced reactive oxidative stress. ${ }^{39} \mathrm{This}$ process further promotes proinflammatory cytokine release, prooncogenic signals, and epigenetic changes. Importantly, these cascades of events may take place in the absence of cirrhosis. In fact, case reports have been published where HCC arose in patients with NASH in the absence of cirrhosis. ${ }^{40}$

Most of the data that examines the cause-effect relationship between NASH and HCC are population-based cohort and case-control studies. In general, these studies support the link between NAFLD and HCC by showing that patients who are obese and have diabetes mellitus type 2 are twice as likely to develop HCC compared to non-obese and nondiabetic patients. ${ }^{41-44}$ In a recent prospective study from the Cleveland clinic, the yearly cumulative incidence of $\mathrm{HCC}$ in patients with NASH was found to be similar to that associated with HCV infection $-2.6 \%$ in patients with NASH-cirrhosis compared with $4 \%$ in patients with HCV cirrhosis. ${ }^{45}$ NAFLD-NASH is an emerging risk factor for $\mathrm{HCC}$ with the potential to contribute and eventually overtake $\mathrm{HCV}$ as the main risk factor for HCC given the galloping rates of obesity and diabetes in the developed world. Efforts should continue to better understand the implications and risks of NAFLD-NASH for HCC.

\section{Other risk factors}

In Asia and Africa, exposure to dietary aflatoxin is an important risk factor for the observed high rate of HCC. Aflatoxin is well known to be both an independent risk factor for HCC and act as a cofactor in chronic HBV infection. ${ }^{46}$ In subSaharan Africa, human immunodeficiency virus infection is recognized as a frequent cofactor that increases the risk of $\mathrm{HCC}$ in patients with chronic HBV or HCV infection. ${ }^{47}$ Another contributable risk factor is tobacco use, which is being identified with increasing frequency in epidemiological studies. In addition, as the vast majority of cases of HCC arise in the setting of cirrhosis, less common causes of cirrhosis such as autoimmune hepatitis, alpha- 1 antitrypsin deficiency, or hereditary hemochromatosis increase the risk of the development of HCC. Figure 4 shows the major factors associated with cirrhosis and HCC.

\section{Prevention}

\section{Antiviral treatment}

The main preventive strategy for the development of HCC in chronic HBV and HCV infection is treatment with antiviral therapy. One large, randomized double blind controlled trial in Chinese patients with hepatitis $\mathrm{B}$ e antigen positive chronic HBV infection with high serum levels of HBV DNA and advanced fibrosis showed that compared to patients treated with placebo, patients treated with lamivudine had less disease progression and incidence of $\mathrm{HCC} .{ }^{48} \mathrm{~A}$ pooled analysis of several nonrandomized studies of interferontreated patients with HCV showed a significant reduction in the incidence of HCC in patients who achieve viral eradication with treatment compared with nonresponders. ${ }^{49}$ The lower incidence of $\mathrm{HCC}$ is also observed in patients with HCV cirrhosis who achieve viral eradication after antiviral therapy. ${ }^{50}$ However, while achievement of a sustained virologic response lowers the risk for $\mathrm{HCC}$, it does not eliminate the risk of $\mathrm{HCC}$ in $\mathrm{HCV}$-related cirrhosis. These findings certainly suggest that patients with cirrhosis should continue surveillance because the risk of occurrence of HCC was 


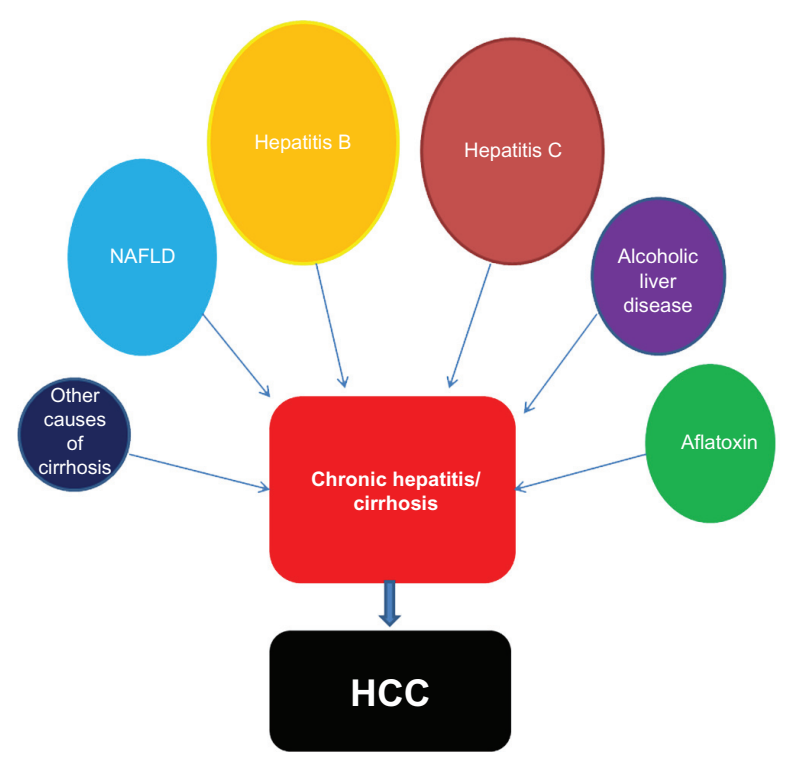

Figure 4 Risk factors for developing hepatocellular carcinoma.

Abbreviations: HCC, hepatocellular carcinoma; NAFLD, nonalcoholic fatty liver disease.

not entirely avoided. Long term antiviral (maintenance) therapy in patients with $\mathrm{HCV}$ cirrhosis, who did not have a sustained response to initial antiviral therapy, did not significantly reduce the risk of HCC after a short followup of 4 years. ${ }^{51} \mathrm{~A}$ more recent analysis of this Hepatitis $\mathrm{C}$ Antiviral Long-term Treatment against Cirrhosis (HALT-C) cohort providing extended follow-up (6 years) showed that maintenance interferon therapy did lower the risk of HCC among patients with cirrhosis, but not advanced fibrosis. ${ }^{52}$ Most of the studies in viral hepatitis show that antiviral therapies for chronic $\mathrm{HBV}$ and $\mathrm{HCV}$ infection can prevent $\mathrm{HCC}$, but do not completely eliminate risk of developing HCC. ${ }^{53}$

Caffeine intake, particularly in the form of coffee, deserves discussion since several observational studies have demonstrated a hepatoprotective effect by showing that coffee drinking is associated with a reduced risk of HCC. ${ }^{54}$ While the mechanisms of this action and the exact amount of coffee consumption necessary to obtain a benefit are unclear, research in this area is ongoing.

\section{Surveillance}

All patients at high risk of developing $\mathrm{HCC}$ are recommended by the practice guidelines from the American Association of the Study of Liver Diseases (AASLD) to be enrolled in formal surveillance. ${ }^{55}$ Surveillance is considered costeffective when the annual incidence of HCC in a population is greater than $1.5 \%$ per year. The groups of patients for whom surveillance is indicated are listed in Table 1. In general, surveillance is recommended for all patients with

cirrhosis regardless of cause and for HBV carriers without cirrhosis if they are Africans older than 20 years of age, Asians older than 40 years of age, or if they have a family history of HCC. The goal of surveillance is to detect HCC early so curative treatments can be applied with improved outcomes. The surveillance strategy recommended is an ultrasound (US) of the liver every 6 months. The use of US as the primary means of surveillance for HCC in at-risk populations has long been recommended in clinical guidelines. US has the advantage of being noninvasive and inexpensive, but operator experience is a crucial factor in overall sensitivity. ${ }^{56}$ Systemic reviews evaluating standard US alone demonstrate a range of sensitivity for $\mathrm{HCC}$ from $30 \%-70 \% .^{57,58}$ On US, HCC lesions will typically appear as hypoechoic lesions. ${ }^{59}$

There are many studies which examined the efficacy of surveillance in early detection and also in improving

Table I Groups for whom surveillance for hepatocellular carcinoma is recommended by the 2010 American Association of the Study of Liver Diseases practice guidelines

Cirrhosis secondary to:

Viral hepatitis (B, C)

Primary biliary cirrhosis

Genetic hemochromatosis

Alpha I-antitrypsin deficiency

Nonalcoholic fatty liver disease

Other causes of cirrhosis

Notes: Copyright (C) 2005. Reprinted with permission from John Wiley and Sons. Bruix J, Sherman M. Management of hepatocellular carcinoma. Hepatology. 2005;42(5): 1208-1236. Updated July 2010. Available from: www.aasld.org/practiceguidelines/ Documents/Bookmarked\%20Practice\%20Guidelines/HCCUpdate20I0.pdf. Accessed February 20, 2012.55 
survival, which are the ultimate goals of any population-based screening strategy. However, robust evidence in support for screening is lacking since it would be unethical to randomize at-risk patients into screened and nonscreened groups in order to compare outcomes. The best level of evidence comes from one randomized controlled trial involving the Chinese population with chronic hepatitis B using abdominal US and alpha-fetoprotein (AFP) every 6 months, showing a reduction in mortality with this screening strategy. ${ }^{60}$ Additional evidence in support of surveillance showing a survival benefit comes from observational studies. ${ }^{61,62}$ From these studies it is accepted that earlier detection of $\mathrm{HCC}$ does improve survival and that it is cost-effective. But despite several guidelines emphasizing the importance of screening it has been shown that only a small percentage of patients with cirrhosis actually undergo periodic surveillance. In a recent population-based cohort identified from the linked Surveillance, Epidemiology, and End Results registry-Medicare databases, less than $20 \%$ of patients who developed HCC had received regular surveillance. ${ }^{63}$

In the updated practice guidelines by the AASLD for HCC, obtaining the AFP serum level was not recommended as a screening test due to its inadequate sensitivity. In a systematic review of literature, when AFP $>20 \mathrm{mcg} / \mathrm{L}$ is used as a cutoff, the sensitivity of detecting early $\mathrm{HCC}$ is reported to be $25 \%-65 \%$ and specificity to be $80 \%-94 \%{ }^{64}$ The low sensitivity makes the use of AFP as the sole screening strategy less desirable. But the largest randomized controlled trial which showed improved survival with surveillance did use AFP as an adjunct with US for screening. Though the AASLD practice guidelines have excluded AFP from their recommendation, the European Association for the Study of the Liver did recommend the use of US with AFP for surveillance. ${ }^{65}$ In the background of existing inadequacies in screening practices, complete exclusion of AFP - an easily available cost-effective tool - is considered controversial. ${ }^{66,67}$ Other serum markers for HCC, such as Lens culinaris agglutinin-reactive AFP (AFP L3), des-gamma carboxyprothrombin, glypican 3, human hepatocyte growth factor, and insulin-like growth factor, garnered initial interest, but require more robust confirmatory studies since studies show them to provide limited use as a sole screening strategy when compared with AFP alone. ${ }^{68,69}$

\section{Diagnosis}

HCC can be diagnosed by noninvasive imaging using its unique dynamic behavior on contrast-enhanced computerized tomography $(\mathrm{CT})$ or magnetic resonance imaging
(MRI). The typical vascular profile of HCC on dynamic imaging is early arterial phase enhancement followed by loss of enhancement in the portal venous and delayed phases compared to the rest of the liver. This imaging characteristic lends itself to the diagnosis of HCC with a sensitivity of $90 \%$ and specificity of $95 \% .^{70}$

\section{US}

Another imaging option to diagnose $\mathrm{HCC}$ once a hepatic nodule is detected on standard US may include contrast-enhanced US. Efforts to improve the sensitivity of standard US have evolved into a medium known as phase-inversion harmonic contrast-enhanced imaging, which utilizes microbubble contrast agents. The use of the contrast medium allows microflow imaging, which demonstrates the vascularity of the lesions in great detail. ${ }^{71} \mathrm{HCC}$ lesions are typically characterized by arterial hyperenhancement, with hypoenhancement in the portal venous and delayed phases, similar to CT and MRI. ${ }^{72}$ A large multicenter study of over 1300 patients with liver tumors demonstrated a diagnostic accuracy of $85 \%$ for HCC with modern contrast-enhanced US. ${ }^{73}$ A subsequent prospective study of 317 patients with hepatic masses showed that contrast-enhanced US had a sensitivity of $90 \%$, a specificity of $99 \%$, and a diagnostic accuracy of $89 \% .{ }^{74}$ However, recent studies have raised concern over this technology because of its inability to adequately differentiate cholangiocarcinoma from $\mathrm{HCC}$, causing a false positive $\mathrm{HCC}$ diagnosis in patients with cholangiocarcinoma. Thus, contrast-enhanced US it is not recommended by the AASLD practice guidelines as a diagnostic technique.

\section{CT}

$\mathrm{CT}$ is the modality used in most centers to make the radiological diagnosis of HCC after a liver nodule is detected on US. Most centers conduct a four-phase multidetector CT (MDCT) scan, which consists of a non-enhanced phase, an arterial phase (which occurs 20-30 seconds after contrast injection), a portal venous phase (which occurs 65-80 seconds after contrast injection), and a delayed phase. On the four-phase CT, HCC will classically appear as a hyperattenuated lesion in the arterial phase, with loss of enhancement termed rapid washout in the portal venous and/or delayed phase. CT has fairly high specificity but variable sensitivity for detecting HCC. A systematic review found that traditional spiral CT had a specificity of $93 \%$ but a sensitivity of only $68 \%$ in diagnosing HCC. A subsequent review of the performance of the newer 64-slice MDCT technology versus spiral CT showed improved sensitivity $(65 \%-79 \%$ compared to $37 \%-54 \%)$ with specificity 
maintained above 90\%. ${ }^{75}$ However, sensitivity continues to be a challenge for small lesions dropping to $33 \%-45 \%$, particularly for those less than $1 \mathrm{~cm}$.

\section{MRI}

MRI is an appealing imaging modality since it does not use ionizing radiation. Instead, MRI uses magnetic fields to induce and detect a signal that allows greater differentiation between neoplastic tissue and normal liver parenchyma even without the use of contrast media, making it an attractive option for the diagnosis and staging of HCC.$^{76}$ Traditional dynamic contrastenhanced MRI of the liver is performed using gadolinium chelates. In gadolinium-enhanced MRI, the typical HCC lesion has hyperintense signal intensity on T1-weighted images during the arterial phase and rapid washout during portal venous and delayed phases. ${ }^{77-79}$ Standard gadolinium-enhanced MRI has a sensitivity of at least $90 \%$ and a specificity of at least $95 \%$ for the detection of HCC for tumors greater than $2 \mathrm{~cm}$ in diameter. ${ }^{80}$ The majority of the studies show dynamic MRI to be superior to CT for detecting HCC lesions. ${ }^{81,82}$ However, as with the other imaging modalities discussed above, the sensitivity of standard MRI decreases for HCC lesions smaller than $2 \mathrm{~cm}$, where it can be as low as $30 \% .{ }^{83,84}$

Recently, targeted contrast agents have been developed in an effort to improve the sensitivity of MRI for HCC. These include the "dual contrast" agents gadoliniumethoxybenzyl-diethylenetriaminepentaacetic acid (Primovist ${ }^{\mathrm{R}}$ and Eovist ${ }^{\circledR}$ in Europe and the United States, respectively) and gadobenate dimeglumine (Gd-BOPTA/Dimeg, MultiHance $\left.{ }^{\circledR}\right)$. These agents serve both as markers of hepatobiliary excretion and vascularization. Typical HCC lesions imaged with these contrast agents will not display uptake, unlike benign nodules on the delayed hepatobiliary phase. ${ }^{85}$ While it appears that gadolinium-ethoxybenzyldiethylenetriaminepentaacetic acid-enhanced MRI performs similarly to MDCT for diagnosis of HCC lesions larger than $2 \mathrm{~cm}$ in diameter, enhanced MRI might be slightly more sensitive than MDCT for lesions smaller than $1 \mathrm{~cm}$ in diameter (with a trend towards statistical significance). ${ }^{86}$

\section{Nuclear imaging}

In general, HCC has low fluorodeoxyglucose avidity in positron emission tomography due to the variable uptake of fluorodeoxyglucose, which is dependent on the differentiation of tumor. Typically, poorly- to moderately-differentiated tumors light up on positron emission tomography scans. The sensitivity of positron emission tomography for detecting HCC can be $40 \%-50 \%$, and this poor sensitivity is why it is not recommended as a screening tool. ${ }^{87}$ Recently, the alternative tracer of C11acetate has been introduced to improve the ability to visualize HCC ${ }^{88}$ While well-differentiated $\mathrm{HCC}$ demonstrates negative fluorodeoxyglucose uptake and positive $11 \mathrm{C}$-acetate uptake, poorly-differentiated HCC displays the reverse characteristics. The combined use of fluorodeoxyglucose and C11-acetate in $\mathrm{HCC}$ has been proposed as a strategy to improve detection on nuclear imaging. However, other studies show that even with the combination of tracers the sensitivity for detecting small HCC remains poor. ${ }^{89}$ Further studies are needed to better define the role of nuclear imaging in patients with HCC.

\section{Diagnostic algorithm}

The most recent AASLD practice guidelines updated the diagnostic algorithm for $\mathrm{HCC}$ in patients with cirrhosis who have hepatic nodules detected on surveillance US imaging (Figure 5). The diagnostic approach depends on the size of the nodule and can involve a sequence of events such as repeat imaging and biopsy. The diagnosis is heavily based on a single dynamic imaging technique showing intense arterial uptake followed by loss on enhancement or "washout." This typical imaging characteristic of HCC has been validated and shown diagnostic accuracy with a single imaging technique. ${ }^{90,91,99}$ The nodules that are less than $1 \mathrm{~cm}$ have a low likelihood of being HCC and are recommended to be followed with imaging every 3 months in order to detect growth suggestive of malignant transformation. The absence of growth during a monitoring period between 1-2 years implies a low likelihood of HCC, while enlargement over this period suggests malignancy and warrants further investigation. For nodules larger than $1 \mathrm{~cm}$ it is recommended to evaluate with either a four-phase MDCT or dynamic MRI. If the greater than 1-cm lesion displays the typical HCC dynamic features, then the lesion is diagnosed and treated as HCC. If the vascular profile is not typical, then a second sequential contrast enhanced imaging (MRI or MDCT) study is performed. If both the arterial hypervascularity and washout are seen on the second imaging study, then the diagnosis of HCC is made. If the lesion appears atypical for HCC on this sequential imaging study, then image-guided core biopsy should be considered. However, biopsies of small tumors less than $2 \mathrm{~cm}$ can yield false negative rates as high as $30 \%-40 \%$ and the small size of the lesions can be difficult to target. Further, biopsies can be associated with a risk of tumor seeding along the needle track, but a recent review reports this occurrence is low $(2.7 \%) .{ }^{92}$ Interpretation of biopsies is challenging, particularly when trying to differentiate between high-grade dysplastic nodules and HCC. For this reason, the guidelines highly encourage 


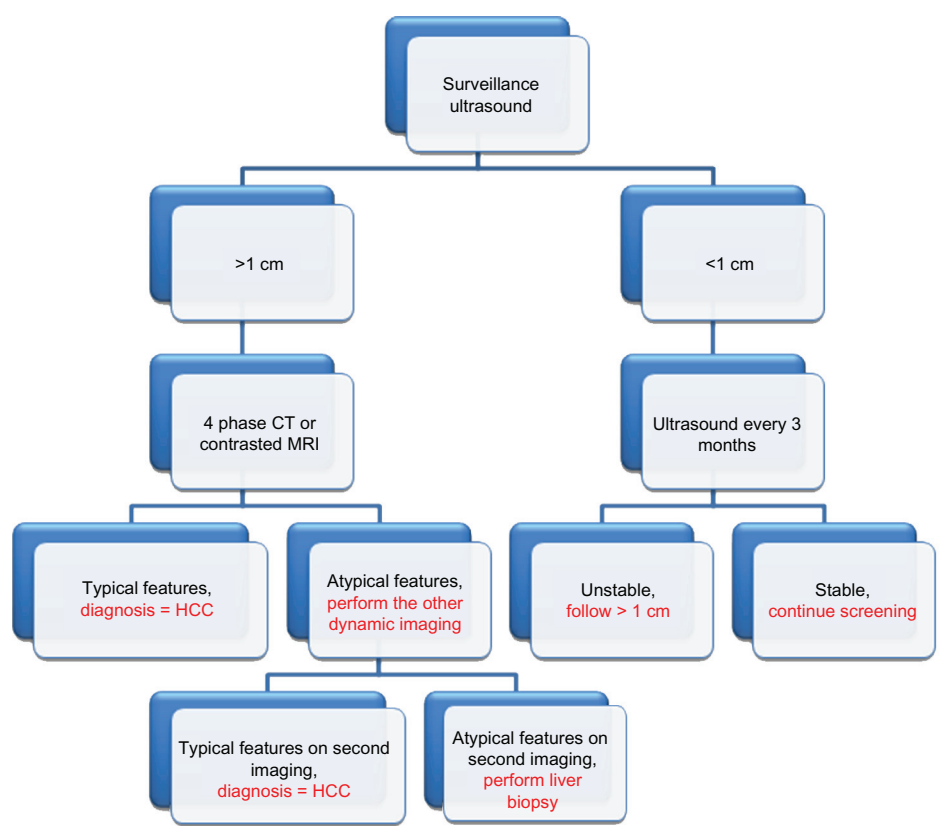

Figure 5 Diagnostic algorithm to diagnose hepatocellular carcinoma as recommended by the American Association of the Study of Liver Diseases 2010 practice guidelines. Notes: Copyright ( ) 2005. Reprinted with permission from John Wiley and Sons. Bruix J, Sherman M. Management of hepatocellular carcinoma. Hepatology. 2005 ;42(5):I208-1236. Updated July 2010. Available from: www.aasld.org/practiceguidelines/Documents/Bookmarked\%20Practice\%20Guidelines/HCCUpdate20I0.pdf. Accessed February 20, 20I2.55

Abbreviation: HCC, hepatocellular carcinoma.

expert pathology review by reinforcing the use of immunostains for glypican 3 , heat shock protein 70 , and glutamine synthetase since positivity for two of these three stains confirms HCC..$^{93}$ The recommended sequential approach with dynamic imaging studies in the algorithm decreases the number of potential biopsies but emphasizes the importance of strict adherence to diagnostic imaging protocols.

\section{Staging}

While several staging systems for HCC exist, the Barcelona Clinic Liver Cancer (BCLC) staging and prognostic system has emerged as the most widely accepted in clinical practice as it incorporates tumor stage, cirrhosis stage, and functional performance status (PS), and links stage with a treatment algorithm (Table 2).$^{94}$ Further, this staging system is endorsed by both American and European liver societies and has been independently validated in European and American cohorts. ${ }^{95,96}$ BCLC identifies several stages of $\mathrm{HCC}$, each of which is associated with a different prognosis and treatment recommendation based on the impact of treatment on survival.

Very early stage HCC (stage 0 ) has the best prognosis, but is unfortunately the hardest to diagnose, as it presents with one lesion smaller than $2 \mathrm{~cm}$ in diameter. Patients in this stage have stable cirrhosis (Child-Pugh class A), and the tumor displays no evidence of vascular invasion. Patients with early stage HCC (stage A) present with either a solitary lesion or up to three lesions each up to $3 \mathrm{~cm}$ in diameter. These patients have preserved liver function (Child-Pugh class A or B) and reasonable functional status (PS 0-2). Patients with stage A HCC can expect 5 -year survival rates of $50 \%-75 \%$, with the choice of treatment dictated by the presence or absence

Table 2 The Barcelona Clinic Liver Cancer staging system for hepatocellular carcinoma

\begin{tabular}{|c|c|c|c|}
\hline & $\begin{array}{l}\text { Performance } \\
\text { status }\end{array}$ & $\begin{array}{l}\text { Tumor } \\
\text { burden }\end{array}$ & $\begin{array}{l}\text { Liver } \\
\text { function }\end{array}$ \\
\hline \multicolumn{4}{|l|}{ Stage A (early) } \\
\hline Al & 0 & Single, $<5 \mathrm{~cm}$ & No PHT \\
\hline $\mathrm{A} 2$ & 0 & Single, $<5 \mathrm{~cm}$ & $\begin{array}{l}\text { PHT, normal } \\
\text { bili }\end{array}$ \\
\hline $\mathrm{A} 3$ & 0 & Single, $<5 \mathrm{~cm}$ & $\begin{array}{l}\text { PHT, } \\
\text { elevated bili }\end{array}$ \\
\hline A4 & 0 & Up to $3,<3 \mathrm{~cm}$ & $\begin{array}{l}\text { Child-Pugh } \\
\text { class A-B }\end{array}$ \\
\hline $\begin{array}{l}\text { Stage B } \\
\text { (intermediate) }\end{array}$ & 0 & Large multinodular & $\begin{array}{l}\text { Child-Pugh } \\
\text { class A-B }\end{array}$ \\
\hline $\begin{array}{l}\text { Stage C } \\
\text { (advanced) }\end{array}$ & $1-2$ & $\begin{array}{l}\text { Vascular invasion or } \\
\text { extrahepatic disease }\end{array}$ & $\begin{array}{l}\text { Child-Pugh } \\
\text { class A-B }\end{array}$ \\
\hline $\begin{array}{l}\text { Stage D } \\
\text { (end stage) }\end{array}$ & $3-4$ & Any & $\begin{array}{l}\text { Child-Pugh } \\
\text { class } C\end{array}$ \\
\hline
\end{tabular}

Notes: Copyright (c) 2005. Reprinted with permission from John Wiley and Sons. Bruix J, Sherman M. Management of hepatocellular carcinoma. Hepatology. 2005;42(5):1208-1236. Updated July 2010. Available from: www.aasld.org/ practiceguidelines/Documents/Bookmarked\%20Practice\%20Guidelines/HCC Update2010.pdf.Accessed February 20, 2012.55

Abbreviations: PHT, portal hypertension; bili, total bilirubin. 
of portal hypertension, the degree of liver dysfunction, and other medical comorbidities.

Intermediate stage HCC (stage B) presents as multinodular HCC, but these patients continue to display preserved liver function (Child-Pugh class A or B) and good functional status (PS 0), and have no cancer-related symptoms or evidence of vascular invasion. Transarterial therapy confers a survival benefit to patients with stage B HCC. Patients with evidence of vascular invasion or extrahepatic spread have advanced stage HCC (stage C). These patients typically have some compromise of functional status (PS 1 or 2) due to HCC, and do receive a survival benefit from treatment with sorafenib.

Patients with terminal stage HCC (stage D) present with decompensated cirrhosis (Child-Pugh class C), poor functional status (PS $>2$ ), and advanced tumor growth (vascular invasion and/or extrahepatic spread). Unfortunately, these patients receive no benefit from the currently available therapies, and survival with symptomatic treatment is around 3 months.

\section{Treatment}

As mentioned above, there are multiple therapeutic modalities available for HCC, and the selection of a particular therapy depends on the stage of HCC, the degree of underlying liver synthetic function, other medical comorbidities, and the availability of the treatment modality and local clinical expertise. These decisions are best made by a multidisciplinary team consisting of hepatologists, surgeons, diagnostic and interventional radiologists, oncologists, and pathologists.

\section{Surgical resection}

Surgical resection represents one potentially curative treatment option for carefully selected patients. It is the ideal treatment for patients with small, solitary nodules without underlying cirrhosis, but this clinical situation is present in less than $5 \%$ of cases. ${ }^{97}$ Most patients with HCC have underlying cirrhosis and require careful evaluation for resection because of the potential for postresection hepatic decompensation. The best candidates for resection are patients with stage 0 or A HCC with Child-Pugh class A cirrhosis characterized by normal portal pressures (hepatic venous pressure gradient $<10 \mathrm{mmHg}$ ) and normal bilirubin (total bilirubin $<1 \mathrm{mg} / \mathrm{dL}) .{ }^{97}$ In these patients with normal bilirubin and the absence of clinically significant portal hypertension (lack of esophageal varices and splenomegaly with less than 100,000 platelets or hepatic venous pressure gradient is under $10 \mathrm{mmHg}$ ), there is minimal risk of postoperative liver failure and they achieve a 5-year survival of 70\% compared to $30 \%$ for those with a bilirubin of more than $1 \mathrm{mg} / \mathrm{dL}$ and portal hypertension..$^{98}$ Interestingly, a Japanese study by Ishizawa et al concluded that resection can provide survival benefits for patients with multiple tumors in a background of Child-Pugh class A cirrhosis and also for patients with portal hypertension. ${ }^{99}$ But there is no consensus yet on extending resection to these patients. ${ }^{100}$ The minimal critical size of the future liver remnant after resection to avoid postresection liver failure is $25 \%$ in the presence of a normal liver and $50 \%$ in patients with cirrhosis. ${ }^{101}$ When the anticipated future liver remnant volume is below these criteria, ipsilateral portal vein embolization is often utilized to increase the volume of the future remnant and increase the safety of the resection. ${ }^{102}$

Unfortunately, after resection the majority of patients develop recurrence with most series reporting 5-year recurrence rates exceeding $70 \% .{ }^{103,104}$ If the tumor recurs and the tumor burden is within the Milan criteria, then salvage LT is being reported as a potential therapeutic strategy. ${ }^{105,106}$ Presently, there is a lack of effective adjuvant therapies to prevent recurrence after resection. Several approaches have failed when taken into larger trials, such as the use of retinoid and vitamin K2. ${ }^{107}$ Results from the Phase III randomized trial comparing sorafenib to placebo as an adjuvant therapy after resection or ablation (STORM [Sorafenib as Adjuvant Treatment in the Prevention of Recurrence of HCC] trial) to prevent recurrence is eagerly awaited since it has completed enrollment. Another Phase III study is planned using an inhibitor of the enzyme heparanase involved in metastasis (PI-88) after showing promising results in a Phase II study. ${ }^{108}$

\section{Transplantation}

LT is another curative option for patients with HCC. For patients with decompensated cirrhosis (Child-Pugh B and C cirrhosis), LT is the most viable treatment option since they can't undergo resection due to marginal liver function. The initial experiences with LT for HCC were dismal with high posttransplant recurrence rates and poor 5-year survival due to poor patient selection. The seminal study published by Mazzaferro et al in 1996 established the tumor burden best handled with LT. ${ }^{109}$ This study showed that patients with tumors confined to the liver within the Milan criteria - defined as having one lesion $\leq 5 \mathrm{~cm}$ or up to three lesions $\leq 3 \mathrm{~cm}$ in diameter, a 5-year survival rate of $>70 \%$, and a low tumor recurrence rate of $<15 \%$ - are the best LT candidates. This degree of tumor burden is compatible with early stage HCC using the BCLC staging system, and LT is now widely accepted as a standard treatment for this stage 
of disease. In general, LT is seen as superior to resection since transplantation has much lower rates of recurrence, which is the main cause of long-term death in resection, and since it treats both the HCC and cirrhosis.

Currently, the United Network for Organ Sharing uses the Model for End-stage Liver Disease (MELD) score to stratify patients based on their risk for short-term mortality, and those with higher scores get transplanted earlier. Since patients with HCC are at higher risk of succumbing to tumor progression than to sequela of cirrhosis, they are assigned a higher MELD score based on the radiologic diagnosis of HCC within the Milan criteria to facilitate earlier transplant. Initially patients with $\mathrm{HCC}$ received a score of 22 for T1 HCC and 29 for T2 HCC. But after studying the outcomes and perceived unfair advantage of this higher score, modification has now been made: no MELD exception points for T1 and 22 for T2. ${ }^{110}$ For each 3-month period in which the patient remains on the waiting list, three additional MELD points are awarded based on the expected $10 \%$ increase in pretransplant mortality while on the waiting list.

Since HCC can progress while patients are on the transplant list, locoregional bridging therapies such as chemoembolization and radiofrequency ablation (RFA) are routinely employed to maintain the tumor burden within Milan criteria and prevent dropout on the waiting list. Several studies, including one from the authors' center, have not demonstrated a survival benefit in employing these interventions. ${ }^{11-113}$ But other studies have suggested the efficacy of pretransplant locoregional therapy in preventing progression and decreasing dropout rates from the transplant list. ${ }^{114,115}$ Current guidelines recommend the use of locoregional therapy for bridging to transplant only if the anticipated time on the waiting list is longer than 6 months. ${ }^{116}$ In order to determine if a true oncologic benefit exists with the use of these interventions, adequately designed and prospective randomized studies are needed.

For those beyond the United Network for Organ Sharing criteria, downstaging the size and numbers of HCC lesions with one or a combination of locoregional treatments can be a successful strategy in close to half of patients, as shown by the University of California at San Francisco protocol. ${ }^{117}$ However, the safety of expanding the Milan criteria has not been established and overall there is no current consensus on the expansion of criteria for transplant eligibility.

\section{Locoregional therapy}

In patients with early stage $\mathrm{HCC}$ who are not eligible for resection or transplantation, several forms of locoregional therapy, such as RFA, percutaneous alcohol injection (PEI), cryoablation, and transarterial therapies, can be used.

\section{RFA and PEI}

The two most commonly used techniques to ablate early stage HCC are RFA and PEI. PEI causes coagulation necrosis of tumors by cellular dehydration, thereby achieving complete tumor necrosis in $90 \%-100 \%$ of the HCC tumors less than $2 \mathrm{~cm}, 70 \%-80 \%$ of the HCC tumors between 2-3 cm, and $50 \%$ in HCC tumors between $3-5 \mathrm{~cm} .{ }^{118,119} \mathrm{PEI}$ is popular due to its low rate of adverse events and being an inexpensive procedure. The major drawback is its high local recurrence rate which requires repeated injections particularly for lesions larger than $3 \mathrm{~cm}$ since the ethanol can't access the entire tumor volume. RFA causes thermal necrosis to tumors by delivering electromagnetic energy through single or multiple needle electrodes inducing a wider region of complete tumor necrosis, and because of this has largely replaced PEI. The decision regarding which technique to employ is usually based on tumor size, tumor location, presence of portal vein thrombus, and local expertise. For small tumors, RFA has been shown to be more efficacious than PEI in a meta-analysis and also in a randomized trial in terms of local disease control, less operator variability, less local recurrence ( $8 \%-14 \%$ versus $22 \%-34 \%$ ), and overall survival (100\% and $98 \%$ versus $96 \%$ and $88 \%$ for 1 year and 2 years, respectively). ${ }^{120,121}$ RFA is the preferred ablative technique for patients with small tumors located away from major vessels and diaphragm. Hence, RFA is currently the first-line therapy employed in this patient group. However, RFA can be associated with pain, intraperitoneal bleeding, tumor seeding, hepatic abscess formation, bile duct injury, and hepatic decompensation. Further, RFA also has limitations in terms of tumor location where it may be contraindicated in certain areas of the liver due to the potential damage to adjacent tissues and loss of efficacy due to large blood vessels causing the heat-sink phenomena. For these reasons, PEI can still be used for small tumors.

Newer ablative techniques are also being investigated. One new technique for local ablation is using microwave technology to induce an ultra-high-speed alternating electric field. ${ }^{122}$ Irreversible electroporation (NanoKnife ${ }^{\circledR}$ System; AngioDynamics, Latham, NY) is another ablation technique in which microsecond to millisecond electrical pulses are delivered to the tumor leading to necrosis through irreversible cell membrane permeabilization. ${ }^{123}$ The advantages of this technique over RFA include its potential to spare adjacent vasculature, lack of detrimental effects on surrounding architecture, and the ability to control and monitor the affected 
area with electrical impedance tomography. ${ }^{123}$ The safety and efficacy of irreversible electroporation is being investigated in a multicenter European prospective pilot trial for the treatment of early stage HCC and has recently completed enrollment. ${ }^{124}$ A third strategy being investigated to improve the efficacy of RFA is ThermoDox ${ }^{\circledR}$. This drug delivery method uses a temperature-sensitive version of liposomal doxorubicin, which after intravenous administration rapidly releases the drug at the tumor site being heated with RFA leading to enhanced necrosis. ${ }^{125}$ These novel techniques for tumor ablation can overcome the limitations of RFA, and further studies are highly awaited to determine their potential applicability and incorporation into current treatment paradigms for early HCC.

\section{Transarterial therapies}

For patients presenting with intermediate stage HCC, transarterial chemoembolization (TACE) is the standard clinical treatment. The dual blood supply of the liver and arterialization of HCC allows the administration of chemotherapeutic and embolizing agents selectively into the artery supplying the tumor. Two randomized controlled trials demonstrated the clinical benefit of TACE over symptomatic supportive care in select patients with unresectable, multifocal HCC with adequate liver function. One randomized study included predominantly patients with HCV-related cirrhosis and showed a survival advantage for TACE at 1 year $(82 \%)$ and 2 years $(63 \%)$ compared to controls at 1 year $(63 \%)$ and 2 years (27\%). ${ }^{126}$ The second randomized study included mostly HBV patients and also showed significantly better survival for TACE at 1 year (57\%), 2 years ( $31 \%)$, and 3 years (26\%) compared to controls at 1 year $(32 \%), 2$ years $(11 \%)$, and 3 years (3\%). ${ }^{127}$ These two studies and a subsequent meta-analysis show TACE improved 3-year survival rates from $10 \%$ to $40 \%-50 \%$ and median survival from 16 to 20 months. These results established TACE as the standard of care for asymptomatic patients with multinodular HCC with no vascular invasion and with Child-Pugh class A cirrhosis. ${ }^{128}$ For patients with more symptomatic disease with impaired liver function compatible with Child-Pugh B or C disease or portal vein thrombosis, TACE is not an optimal technique and contraindicated. However, some series report a similar treatment-related benefit in HCC patients with portal vein thrombosis using highly selective TACE. ${ }^{129}$ The most common complication in patients treated with TACE is a postembolization syndrome occurring in more than $50 \%$ of patients. Postembolization syndrome consists of transient fever, abdominal pain, nausea, ileus, and elevated alanine aminotransferase. This syndrome is usually self-limited with supportive care, typically lasting between $24-48 \mathrm{hrs}$. Hepatic decompensation in the form of ascites and gastrointestinal bleeding is the most feared complication occurring in less than $10 \%$ of patients. Additional treatment-related side effects from the chemotherapy are nausea, vomiting, bone marrow suppression, alopecia, and, potentially, renal failure.

TACE is now the most widely performed palliative treatment for intermediate stage HCC. The studies establishing TACE as the first-line treatment for locally advanced HCC used selective injection of chemotherapeutic agents along with an oily carrier such as lipoidol into the feeding arteries of the tumor to obtain higher and prolonged local drug concentrations. ${ }^{130}$ An embolic material was then injected that caused ischemia and necrosis. A wide range of side effects have been reported in the literature with this technique such as post-TACE syndrome, intrahepatic biloma, acute hepatic failure, liver infarction, abscess formation, and chemotherapy-related systemic toxicities. ${ }^{131}$ In addition, when TACE is applied in clinical practice, a number of variables exist that contribute to the heterogeneous nature of the technique, such as the type of anticancer drugs (eg, doxorubicin, cisplatin, or epirubicin) and dose, the choice of embolic agent (eg, gelfoam, polyvinyl alcohol, or microspheres), delivery, timing, selectivity, the treatment schedule (on demand based on residual tumor or fixed schedule), and whether embolization is done to complete or near stasis. ${ }^{132}$

More centers are now using the recently developed doxorubicin-loaded drug-eluting beads TACE (DEB-TACE) (DC Bead ${ }^{\circledR}$; Biocompatibles UK Ltd, Farnham, UK) since delivery with this strategy increases the intratumoral delivery of cytotoxic drugs in a predictable manner that limits systemic adverse events. ${ }^{133,134}$ DEB-TACE minimizes a number of variables inherent with conventional, lipoidol-based TACE technique by using a uniform size of beads with predefined doses of chemotherapy. The beads absorb a predictable concentration of the chemotherapy and upon reaching the tumor vascular bed slowly release the drug in a controlled fashion. The simultaneous release of drug with induction of ischemia as the beads embolize the tumor allows the technique to be performed in a more consistent and reproducible manner.

DEB-TACE was directly compared with conventional, lipoidol-based TACE in a randomized Phase II trial for safety and efficacy. ${ }^{135}$ The DEB-TACE group showed higher rates of complete response, objective response, and disease control compared with the conventional TACE group. However, these differences in the 6-month tumor response (DEB-TACE 63\% versus conventional TACE $52 \% ; P=0.11$ ) was not significant. The use of DEB-TACE was associated with improved 
tolerability marked by significant reduction in doxorubicinrelated side effects and serious liver toxicity. Further, the patients with more advanced features, such as Child-Pugh B cirrhosis, worse PS, and bilobar disease, demonstrated significantly higher tumor response rates with DEB-TACE with improved safety. These findings suggest the DEB-TACE may be used safely in Child-Pugh B cirrhosis which is presently a contraindication for TACE in the AASLD HCC practice guidelines. The association of DEB-TACE with an increase in tumor response and a reduction in both liver and systemic side effects has led to its rapid use at referral centers. Newer modes of transarterial drug delivery are also being developed. An example is the hepaspheres (HepaSphere ${ }^{\mathrm{TM}}$ Microspheres; Merit Medical Systems Inc, South Jordan, UT), which are superabsorbent polymer microspheres undergoing early stage evaluation. ${ }^{136}$

Transarterial brachytherapy or radioembolization is another palliative treatment for intermediate stage HCC. Radioembolization involves hepatic arterial injection of yittrium-90 microspheres (Y-90) as glass (TheraSphere ${ }^{\circledR}$; Nordion, ON, Canada) or resin (SIR-Spheres ${ }^{\circledR}$; Sirtex Medical, Sydney, Australia). The Y-90 particles are smaller in size than the drug-eluding beads used for TACE. Their smaller size allows them to be preferentially trapped at the capillary bed leading to less tumor ischemia and angioneogenesis. Once they obstruct in the tumor capillary bed, then the Y-90 particles can deliver up to $150 \mathrm{~Gy}$ of beta radiation to induce tumor necrosis by radiation and microscopic embolization. ${ }^{137}$ Radiation exposure is limited to adjacent healthy tissue given its radius of action of up to $1 \mathrm{~cm}$ and half-life of 62 hours. The reported literature on Y-90 has been largely from uncontrolled single center experiences. ${ }^{138}$ This American cohort experience used Y-90 glass microspheres and reported survival that differed significantly by the dual competing risks of HCC stage and Child-Pugh status. In this series, patients with Child-Pugh class A cirrhosis and intermediate stage HCC benefited the most with a median survival of 17.2 months, while patients with Child-Pugh class B cirrhosis had the worse outcomes with a median survival of 7.7 months. The largest clinical experience comes from the European Network using the Y-90 glass microspheres and reported a median survival in intermediate stage HCC of 16.9 months and advanced stage HCC of 10 months. ${ }^{139}$ At the present time, Y-90 treatment has not been evaluated in controlled trials directly comparing Y-90 to TACE treatment. Comparison is limited to retrospective studies, one evaluating Y-90 to conventional lipoidol-based TACE that showed statistically similar survival (20.5 months with Y-90 versus 17.4 months with TACE, $P=0.23) .{ }^{140}$ While a direct comparison in a randomized trial is needed, the number of patients needed (more than 1000) based on power calculation to compare both treatments in intermediate stage HCC is a significant barrier. Further evaluation of Y-90 in combination with other agents such as sorafenib seems more reasonable.

\section{Combination TACE and sorafenib}

Chemoembolization results in tumor ischemia and hypoxia which increase pro-angiogenic growth factors such as vascular endothelial growth factor (VEGF). ${ }^{141}$ VEGF can induce angiogenesis in the peripheral parts of the tumor thereby offsetting the desired antitumor effects of TACE. Since angioneogenesis plays a major role in the pathogenesis of HCC, the combination of TACE and angiogenesis inhibitors like sorafenib for intermediate stage HCC has strong rationale. A number of combination strategies are under investigation. One approach shown to be safe and tolerable in early studies is maintaining continuous dosing of sorafenib without stopping as the patients undergo TACE. ${ }^{142}$ The authors' center has examined the safety, tolerance, and efficacy of combining TACE and sorafenib with a protocol that uses concomitant DEB-TACE and sorafenib. ${ }^{143}$ The results showed the combination of TACE and sorafenib is tolerable but is associated with a higher rate of adverse events. The adverse events are similar to the side effect profile observed with sorafenib monotherapy. In addition, the combination did not adversely impact the ability to perform TACE. The combination yielded encouraging efficacy with a disease control rate of $68 \%$ and overall median survival of 18.5 months given that $20 \%$ of the 47 patients had stage C HCC and Child-Pugh class B cirrhosis. Currently, this combination of TACE and sorafenib is undergoing evaluation as part of a multinational, randomized, placebo-controlled trial comparing TACE plus placebo versus TACE plus sorafenib for intermediate stage $\mathrm{HCC}$ with Child-Pugh class A cirrhosis (SPACE [Sorafenib or Placebo in Combination with TACE for Intermediate-Stage HCC] study). The study recently completed enrollment and results are anticipated soon. If the randomized design confirms a benefit to the combination of TACE and sorafenib and tolerability, then this approach can be incorporated into clinical practice.

\section{Sorafenib}

Sorafenib is an oral multikinase/tyrosine kinase inhibitor that has shown a survival benefit over best supportive care in two pivotal studies (SHARP [A Phase III Study of Sorafenib in Patients with Advanced HCC] and Asian 
Pacific trials) in patients with Child-Pugh class A cirrhosis and advanced HCC compatible with stage $\mathrm{C}$ by the BCLC system. ${ }^{144,145}$ Single agent sorafenib for advanced HCC provided a modest benefit with a median improvement in overall survival for sorafenib over placebo of about 3 months. Further, treatment largely stabilized the tumor by delaying progression, reflecting how targeted agents act predominantly through cytostatic pathways. The efficacy of sorafenib in these trials led to its approval by regulatory agencies as the first systemic treatment in advanced HCC and the endorsement of sorafenib as the standard of care for this stage by practice guidelines. The proven benefit of sorafenib has been a major milestone in the treatment of patients with advanced stage HCC who previously lacked any effective treatment. This clinical success has served as a major impetus to further development of molecular-targeted therapies for this cancer.

A number of trials are currently under way to determine the safety and efficacy of sorafenib in combination with other molecular-targeted agents (Table 3). Examples of these studies include a Phase III study comparing sorafenib plus erlotinib (epidermal growth factor receptor [EGFR] inhibitor) to sorafenib plus placebo (SEARCH [Sorafenib and Erlotinib, A Randomized Trial Protocol for the Treatment of Patients with HCC]) and randomized Phase II comparing everolimus (mammalian target of rapamycin inhibitor) plus

Table 3 Ongoing and planned trials in hepatocellular carcinoma

\begin{tabular}{|c|c|c|c|}
\hline $\begin{array}{l}\text { Targeted } \\
\text { population }\end{array}$ & Goal & Design & Phase \\
\hline \multirow[t]{2}{*}{ Adjuvant } & $\begin{array}{l}\text { Prevent } \\
\text { recurrences }\end{array}$ & $\begin{array}{l}\text { I. Sorafenib vs } \\
\text { placebo }\end{array}$ & III \\
\hline & & 2. PI-88 vs placebo & III \\
\hline Early HCC & $\begin{array}{l}\text { Improve } \\
\text { RFA }\end{array}$ & I. RFA + ThermoDox ${ }^{\circledR}$ & III \\
\hline Intermediate & Improve & I. TACE \pm sorafenib & II \\
\hline $\mathrm{HCC}$ & TACE & $\begin{array}{l}\text { 2. } \mathrm{TACE} \pm \text { brivanib } \\
\text { 3. } \mathrm{TACE} \pm \text { ttrium }-90\end{array}$ & $\begin{array}{l}\text { III } \\
\text { II }\end{array}$ \\
\hline Advanced & First line: & I. Sorafenib \pm erlotinib & III \\
\hline \multirow[t]{8}{*}{$\mathrm{HCC}$} & & 2. Sorafenib vs brivanib & III \\
\hline & & 3. Sorafenib vs sunitinib & III (terminated) \\
\hline & & 4. Sorafenib vs sunitinib & III \\
\hline & & 5. Sorafenib vs ABT- 869 & III \\
\hline & & $\begin{array}{l}\text { 6. Sorafenib vs } \\
\text { bevacizumab and } \\
\text { erlotinib }\end{array}$ & III \\
\hline & & $\begin{array}{l}\text { 7. Sorafenib } \pm \\
\text { doxorubicin }\end{array}$ & III \\
\hline & Second line: & I. Brivanib vs placebo & III \\
\hline & & 2. Everolimus vs placebo & III \\
\hline
\end{tabular}

Abbreviations: HCC, hepatocellular carcinoma; RFA, radiofrequency ablation; TACE, transarterial chemoembolization. sorafenib to sorafenib alone. A number of other agents are also being explored in single arm and randomized Phase II studies. Recently, the Phase III study directly comparing sorafenib to sunitinib was terminated early due to a higher incidence of serious adverse events. While sorafenib does improve overall survival in patients with advanced HCC, progressive disease eventually develops in most patients. Failure of sorafenib may reflect the participation of alternative molecular pathways driving tumor progression. In addition to combining agents with sorafenib, ongoing trials are also targeting different molecular pathways not inhibited by sorafenib. An example is brivanib, an oral, selective dual inhibitor of the fibroblast growth factor and VEGF pathway. Brivanib has shown clinical activity and manageable tolerability as a first-line or second-line treatment in a Phase II study for patients with advanced HCC. ${ }^{146}$ The positive results have led to the initiation of Phase III studies with brivanib as a first-line and second-line treatment for advanced HCC as well as in combination with TACE for intermediate stage HCC. ${ }^{147-149}$

Prior to the benefits of sorafenib demonstrated by the Phase III SHARP trial, a randomized Phase II trial of patients with advanced HCC to treatment with sorafenib plus doxorubicin versus doxorubicin alone was performed. ${ }^{150}$ This study was halted once the survival benefit of sorafenib was established, making sorafenib the standard of care for advanced HCC. In this study, sorafenib plus doxorubicin compared doxorubicin monotherapy improved median time to progression, overall survival, and progression-free survival. Presently, a Phase III trial by the United States cooperative group Cancer and Leukemia Group B (80802) is currently enrolling with a study design comparing single agent sorafenib versus sorafenib plus doxorubicin to further clarify if there is synergy with this combination with improved outcomes.

In addition to improving outcomes with newer treatments, there remains some uncertainty about the use of sorafenib in patients with more liver function impairment, such as those with Child-Pugh class B cirrhosis. This concern is important since the majority of patients with HCC in clinical practice may have more compromised liver function and differ from the patients in the pivotal trials that had Child-Pugh class A cirrhosis. Currently, there is limited data on the use of sorafenib in Child-Pugh class B cirrhosis and its use needs to be individualized with close monitoring and an assessment of its risk-benefit profile. Data from the GIDEON (Global Investigation of Therapeutic Decisions on HCC and of its Treatment with Sorafenib) study, which is a large global prospective, noninterventional study of 
patients with unresectable HCC assigned to sorafenib, may provide more information on the safety and efficacy of sorafenib in Child-Pugh class B cirrhosis. An interim analysis reported that compared with Child-Pugh class A patients, Child-Pugh class B patients did not have a higher incidence of drug-related adverse effects, but had a higher incidence of liver-associated adverse effects. Another concern in real-life clinical practice with sorafenib is that full dosing can be challenging and a large percentage of patients require dose reductions. The concern for adverse events in this vulnerable patient population results in the consideration and initiation of lower starting doses by a large number of prescribers as presented by the GIDEON interim analysis. Presently, the authors' center is evaluating an open-label randomized study (RAMP-UP [Sorafenib Dose Ramp-Up in HCC]) to see if increasing the dose of sorafenib slowly over several weeks versus starting with the standard full dose can improve tolerance and drug delivery. ${ }^{151}$

\section{Additional molecular targets for advanced HCC}

Erlotinib (Tarceva ${ }^{\circledR}$ ) is an EGFR tyrosine kinase inhibitor that in a single-arm Phase II trial using erlotinib monotherapy in 38 patients with advanced $\mathrm{HCC}$, a benefit was observed with a median overall survival of 13 months. ${ }^{152}$ When using erlotinib and bevacizumab (Avastin ${ }^{\circledR}$ ) - VEGF antagonists - together in a single-arm Phase II trial in 40 patients with advanced HCC, an impressive median survival of 15.6 months was observed. ${ }^{153}$ This clinically meaningful result has led to a Phase II randomized study of bevacizumab and erlotinib compared to sorafenib monotherapy as a first-line treatment ${ }^{154}$ and as a second-line treatment ${ }^{155}$ for advanced HCC. Lapatinib $\left(\right.$ Tykerb $\left.^{\circledR}\right)$ is another inhibitor of EGFR that also blocks the human epidermal growth factor receptor 2 pathways. Phase II trials with lapatinib for advanced HCC have shown that this agent was well tolerated, but therapy did not meet the predefined efficacy rate. ${ }^{156,157}$ Similar to lapatinib, other agents targeting the EGFR pathway as monotherapy, such as gefinitib (Iressa ${ }^{\circledR}$ ) and cetuximab $\left(\right.$ Erbitux $^{\circledR}$ ), failed to show significant evidence of clinical activity. ${ }^{158,159}$ Cetuximab, the chimeric monoclonal antibody against EGFR, in combination with gemcitabine and oxaliplatin in a single-arm study with 45 advanced HCC patients was associated with hematologic toxicity that consisted of thrombocytopenia (24\%), neutropenia (20\%), and anemia (4\%), and a median overall survival of 9.5 months. ${ }^{160}$

Other drugs targeting various molecular pathways under active investigation for treatment of advanced HCC include: linifanib (ABT-869) in a Phase III study being compared with sorafenib; ${ }^{161}$ mitogen-activated protein kinase kinase inhibitors (BAY86-9766) in a Phase II study in combination with sorafenib; ${ }^{162}$ mapatumumab (HGS-1012), a human agonist monoclonal antibody to the tumor necrosis factor-related apoptosis-inducing ligand receptor 1 in Phase I-II evaluation in combination with sorafenib; ${ }^{163}$ everolimus (Afinitor ${ }^{\circledR}$ ), an oral mammalian target of rapamycin inhibitor in Phase I-II evaluation for the treatment of advanced HCC; ${ }^{164,165}$ and ramucirumab (IMC-1121B), a human monoclonal antibody that binds to VEGF receptor 2 in a Phase III study as a second-line treatment in patients with advanced HCC who fail first-line treatment with sorafenib (REACH [A Study of Ramucirumab Drug Product and Best Supportive Care Versus Placebo and Best Supportive Care as Second-Line Treatment in Patients With HCC After First-Line Therapy With Sorafenib] study). Ramucirumab was also evaluated in a one-arm Phase II study of 43 patients with advanced HCC. As a single agent in sorafenib-naive patients, it conferred moderate disease control (50\%) and was associated with gastrointestinal bleeding ( $9 \%$; grade $3 / 4$ ), hypertension (14\%; grade 3/4), and infusion-related reactions (5\%; grade 3 ); clinical efficacy was not reported in the abstract. ${ }^{166}$

Brivanib (BMS-582664), a selective dual inhibitor of VEGF receptor and fibroblast growth factor receptor signaling pathways, has been evaluated in a Phase II study as a single agent both as first-line $e^{146,167}$ and second-line ${ }^{167}$ treatment. Raoul et al enrolled a total of 96 patients with advanced HCC, with 55 being treatment-naïve (Cohort A) and 41 having received previous treatment (Cohort $B$ ). In Cohort A, brivanib resulted in a disease control rate of $60 \%$ and was generally well tolerated. The patients had no skin toxicities and the most common adverse events included fatigue (45\%), hypertension (45\%), and diarrhea (42\%). ${ }^{167}$ The median overall survival for the first-line treatment cohort was 10 months. The second cohort of 41 patients (Cohort B) received brivanib as a second-line treatment after failing one prior antiangiogenic therapy - 94\% had progression with sorafenib and $6 \%$ failed thalidomide. This cohort had a lower disease control rate of $46 \%$ but a similar median overall survival of 9.8 months. Brivanib is nearing completion of Phase III trial testing as a first-line treatment versus sorafenib in advanced stage HCC, 147 as a second-line treatment versus placebo in sorafenib failures, ${ }^{148}$ and brivanib versus placebo in combination with TACE. ${ }^{149}$ Unfortunately, the great medical need for a second-line treatment for those that fail sorafenib with advanced stage $\mathrm{HCC}$ will continue since a recent press release by Bristol-Myers Squibb (New York, NY) 
reported that the study did not meet the primary endpoint of improving overall survival versus placebo. ${ }^{168}$

\section{Conclusion}

HCC is a major global public health problem due to the rising incidence and high mortality in both developing and developed countries. In order to mitigate this important worldwide health care challenge, it is critical to detect the cancer early. Early detection allows the application of curative treatments. The epidemiology and risk factors for HCC are well known and vary with geographic region. The prevention strategy of hepatitis $\mathrm{B}$ vaccination is resulting in a decline in hepatitis $\mathrm{B}$, but the incidence of chronic hepatitis C-related HCC is continuing to grow in the developed world. New antiviral therapies and surveillance are available that can lead to improved outcomes by decreasing the likelihood of future HCC and/or diagnosing HCC earlier. Early diagnosis of HCC is critical since the clinical outcome depends to a large extent on the ability to identify this cancer early. Resection and transplantation remain the cornerstones of curative therapy for HCC but several advances in the treatment of unresectable $\mathrm{HCC}$ are beginning to expand the therapeutic armamentarium. The clinical success of sorafenib in advanced HCC has led to an explosion in clinical research using additional targeted therapies alone, in combination with sorafenib, or in combination with liver-targeted therapies looking for synergy and to further improve outcomes. Results from some of these studies are anticipated soon and can potentially change current practice. As new data emerges it will be important that management of this disease continues to be performed by multidisciplinary teams.

\section{Disclosure}

Dr Roniel Cabrera is a consultant and has research grants from Bayer/Onyx and Bristol-Myers Squibb. The authors report no other conflicts of interest in this work.

\section{References}

1. Surveillance Research Program, National Cancer Institute. Fast stats: an interactive tool for access to SEER cancer statistics. November 10, 2011. Available from: http://seer.cancer.gov/faststats. Accessed August 15, 2011.

2. Ferlay J, Shin HR, Bray F, Forman D, Mathers C, Parkin DM. Estimates of worldwide burden of cancer in 2008: GLOBOCAN 2008. Int J Cancer. 2010;127(12):2893-2917.

3. World Health Organization. Hepatitis B fact sheet. August 21, 2008. Available from: http://www.who.int/mediacentre/factsheets/fs204/en/. Accessed February 20, 2012.

4. World Health Organization. Facts and figures: hepatitis C. May 25, 2010. Available from: http://www.euro.who.int/en/what-we-do/health-topics/ communicable-diseases/hepatitis/facts-and-figures/hepatitis-c. Accessed February 20, 2012.
5. Jemal A, Bray F, Center MM, Ferlay J, Ward E, Forman D. Global cancer statistics. CA Cancer J Clin. 2011;61(2):69-90.

6. Kao JH, Chen DS. Changing disease burden of hepatocellular carcinoma in the Far East and Southeast Asia. Liver Int. 2005;25(4): 696-703.

7. Chang MH, You SL, Chen CJ, et al. Decreased incidence of hepatocellular carcinoma in hepatitis B vaccinees: a 20-year follow-up study. J Natl Cancer Inst. 2009;101(19):1348-1355.

8. Yoshizawa H. Hepatocellular carcinoma associated with hepatitis $\mathrm{C}$ virus infection in Japan: projection to other countries in the foreseeable future. Oncology. 2002;62 Suppl 1:8-17.

9. Altekruse SF, McGlynn KA, Reichman ME. Hepatocellular carcinoma incidence, mortality, and survival trends in the United States from 1975 to 2005. J Clin Oncol. 2009;27(9):1485-1491.

10. El-Serag HB, Mason AC. Rising incidence of hepatocellular carcinoma in the United States. N Engl J Med. 1999;340(10):745-750.

11. Howlader N, Noone AM, Krapcho M, et al, editors; National Cancer Institute. SEER cancer statistics review, 1975-2008. November 10, 2011. Available from: http://seer.cancer.gov/csr/1975_2008/.Accessed February 20, 2012.

12. El-Serag HB, Mason AC. Risk factors for the rising rates of primary liver cancer in the United States. Arch Intern Med. 2000;160(21): 3227-3230.

13. Tsukuma H, Hiyama T, Tanaka S, et al. Risk factors for hepatocellular carcinoma among patients with chronic liver disease. $N$ Engl J Med. 1993;328(25):1797-1801.

14. El-Serag HB, Davila JA, Petersen NJ, McGlynn KA. The continuing increase in the incidence of hepatocellular carcinoma in the United States: an update. Ann Intern Med. 2003;139(10):817-823.

15. Parkin DM. The global health burden of infection-associated cancers in the year 2002. Int J Cancer. 2006;118(12):3030-3044.

16. World Health Organization; International Agency for Research on Cancer. IARC Monographs on the Evaluation of Carcinogenic Risks to Humans. Volume 59: Hepatitis Viruses. Lyon, France: International Agency for Research on Cancer; 1994.

17. Nguyen VT, Law MG, Dore GJ. Hepatitis B-related hepatocellular carcinoma: epidemiological characteristics and disease burden. JViral Hepat. 2009;16(7):453-463.

18. But DY, Lai CL, Yuen MF. Natural history of hepatitis-related hepatocellular carcinoma. World J Gastroenterol. 2008;14(11):1652-1656.

19. Feitelson MA. Hepatitis B virus in hepatocarcinogenesis. J Cell Physiol. 1999;181(2):188-202.

20. Sakuma K, Saitoh N, Kasai M, et al. Relative risks of death due to liver disease among Japanese male adults having various statuses for hepatitis B s and e antigen/antibody in serum: a prospective study. Hepatology. 1988;8(6):1642-1646.

21. Amin J, Dore GJ, O'Connell DL, et al. Cancer incidence in people with hepatitis B or C infection: a large community-based linkage study. J Hepatol. 2006;45(2):197-203.

22. Ulcickas Yood M, Quesenberry CP Jr, Guo D, et al. Incidence of hepatocellular carcinoma among individuals with hepatitis B virus infection identified using an automated data algorithm. J Viral Hepat. 2008;15(1):28-36.

23. Chen JD, Yang HI, Iloeje UH, et al. Carriers of inactive hepatitis B virus are still at risk for hepatocellular carcinoma and liver-related death. Gastroenterology. 2010;138(5):1747-1754.

24. Chen CJ, Yang HI, Iloeje UH; REVEAL-HBV Study Group. Hepatitis B virus DNA levels and outcomes in chronic hepatitis B. Hepatology. 2009;49(Suppl 5):S72-S84.

25. Yang HI, Yeh SH, Chen PJ, et al. Associations between hepatitis B virus genotype and mutants and the risk of hepatocellular carcinoma. J Natl Cancer Inst. 2008;100(16):1134-1143.

26. Yang HI, Sherman M, Su J, et al. Nomograms for risk of hepatocellular carcinoma in patients with chronic hepatitis B virus infection. J Clin Oncol. 2010;28(14):2437-2444.

27. Kiyosawa K, Umemura T, Ichijo T, et al. Hepatocellular carcinoma: recent trends in Japan. Gastroenterology. 2004;127(5 Suppl 1):S17-S26. 
28. El-Serag HB. Hepatocellular carcinoma and hepatitis $\mathrm{C}$ in the United States. Hepatology. 2002;36(5 Suppl 1):S74-S83.

29. Williams I. Epidemiology of hepatitis $\mathrm{C}$ in the United States. $A m$ J Med. 1999;107(6B):2S-9S.

30. Centers for Disease Control and Prevention. Hepatitis C information for professionals. November 2010. Available from: http://www.cdc. gov/hepatitis/HCV/StatisticsHCV.htm. Accessed August 27, 2011.

31. Donato F, Boffetta P, Puoti M. A meta-analysis of epidemiological studies on the combined effect of hepatitis B and $\mathrm{C}$ virus infections in causing hepatocellular carcinoma. Int J Cancer. 1998;75(3): 347-354.

32. Donato F, Tagger A, Gelatti U, et al. Alcohol and hepatocellular carcinoma: the effect of lifetime intake and hepatitis virus infections in men and women. Am J Epidemiol. 2002;155(4):323-331.

33. Liang TJ, Heller T. Pathogenesis of hepatitis C-associated hepatocellular carcinoma. Gastroenterology. 2004;127(5 Suppl 1):S62-S71.

34. Hassan MM, Hwang LY, Hatten CJ, et al. Risk factors for hepatocellular carcinoma: synergism of alcohol with viral hepatitis and diabetes mellitus. Hepatology. 2002;36(5):1206-1213.

35. Davis GL, Alter MJ, El-Serag HB, Poynard T, Jennings LW. Aging of hepatitis C virus (HCV)-infected persons in the United States: a multiple cohort model of $\mathrm{HCV}$ prevalence and disease progression. Gastroenterology. 2010;138(2):513-521.

36. Lok AS, Seeff LB, Morgan TR, et al. Incidence of hepatocellular carcinoma and associated risk factors in hepatitis C-related advanced liver disease. Gastroenterology. 2009;136(1):138-148.

37. Neuschwander-Tetri BA, Caldwell SH. Nonalcoholic steatohepatitis: summary of an AASLD Single Topic Conference. Hepatology. 2003; 37(5):1202-1219.

38. Bugianesi E, Leone N, Vanni E, et al. Expanding the natural history of nonalcoholic steatohepatitis: from cryptogenic cirrhosis to hepatocellular carcinoma. Gastroenterology. 2002;123(1):134-140.

39. Stickel F, Hellerbrand C. Non-alcoholic fatty liver disease as a risk factor for hepatocellular carcinoma: mechanisms and implications. Gut. 2010;59(10):1303-1307.

40. Hai S, Kubo S, Shuto T, et al. Hepatocellular carcinoma arising from nonalcoholic steatohepatitis: report of two cases. Surg Today. 2006;36(4):390-394.

41. Calle EE, Rodriguez C, Walker-Thurmond K, Thun MJ. Overweight, obesity, and mortality from cancer in a prospectively studied cohort of US adults. $N$ Engl $J$ Med. 2003;348(17):1625-1638.

42. El-Serag HB, Hampel H, Javadi F. The association between diabetes and hepatocellular carcinoma: a systematic review of epidemiologic evidence. Clin Gastroenterol Hepatol. 2006;4(3):369-380.

43. Mori S, Yamasaki T, Sakaida I, et al. Hepatocellular carcinoma with nonalcoholic steatohepatitis. J Gastroenterol. 2004;39(4):391-396.

44. Hashimoto E, Yatsuji S, Tobari M, et al. Hepatocellular carcinoma in patients with nonalcoholic steatohepatitis. J Gastroenterol. 2009; 44 Suppl 19:89-95.

45. Ascha MS, Hanouneh IA, Lopez R, Tamimi TA, Feldstein AF, Zein NN. The incidence and risk factors of hepatocellular carcinoma in patients with nonalcoholic steatohepatitis. Hepatology. 2010;51(6):1972-1978.

46. Kensler TW, Roebuck BD, Wogan GN, Groopman JD. Aflatoxin: a 50 -year odyssey of mechanistic and translational toxicology. Toxicol Sci. 2011;120 Suppl 1:S28-S48.

47. Mallet V, Vallet-Pichard A, Pol S. The impact of human immunodeficiency virus on viral hepatitis. Liver Int. 2011;31 Suppl 1:135-139.

48. Liaw YF, Sung JJ, Chow WC, et al. Lamivudine for patients with chronic hepatitis B and advanced liver disease. N Engl J Med. 2004;351(15): $1521-1531$

49. Singal AK, Singh A, Jaganmohan S, et al. Antiviral therapy reduces risk of hepatocellular carcinoma in patients with hepatitis $\mathrm{C}$ virus-related cirrhosis. Clin Gastroenterol Hepatol. 2010;8(2):192-199.

50. Bruno S, Stroffolini T, Colombo M, et al; Italian Association of the Study of the Liver. Sustained virological response to interferonalpha is associated with improved outcome in HCV-related cirrhosis: a retrospective study. Hepatology. 2007;45(3):579-587.
51. Di Bisceglie AM, Shiffman ML, Everson GT, et al. Prolonged therapy of advanced chronic hepatitis $\mathrm{C}$ with low-dose peginterferon. $N$ Engl $J$ Med. 2008;359(23):2429-2441.

52. Lok AS, Everhart JE, Wright EC, et al; HALT-C Trial Group. Maintenance peginterferon therapy and other factors associated with hepatocellular carcinoma in patients with advanced hepatitis C. Gastroenterology. 2011;140(3):840-849.

53. Kwon H, Lok AS. Does antiviral therapy prevent hepatocellular carcinoma? Antivir Ther. 2011;16(6):787-795.

54. Larsson SC, Wolk A. Coffee consumption and risk of liver cancer: a meta-analysis. Gastroenterology. 2007;132(5):1740-1745.

55. Bruix J, Sherman M. Management of hepatocellular carcinoma. Hepatology. 2005;42(5):1208-1236. Updated July 2010. Available from: www.aasld.org/ practiceguidelines/Documents/Bookmarked\%20Practice\%20Guidelines/ HCCUpdate2010.pdf. Accessed February 20, 2012.

56. Kudo M, Hirasa M, Takakuwa H, et al. Small hepatocellular carcinomas in chronic liver disease: detection with SPECT. Radiology. 1986;159(3):697-703.

57. Outwater EK. Imaging of the liver for hepatocellular carcinoma. Cancer Control. 2010;17(2):72-82.

58. Colli A, Fraquelli M, Casazza G, et al. Accuracy of ultrasonography, spiral CT, magnetic resonance, and alpha-fetoprotein in diagnosing hepatocellular carcinoma: a systematic review. Am J Gastroenterol. 2006;101(3):513-523.

59. Bennett GL, Krinsky GA, Abitbol RJ, Kim SY, Theise ND, Teperman LW. Sonographic detection of hepatocellular carcinoma and dysplastic nodules in cirrhosis: correlation of pretransplantation sonography and liver explants pathology in 200 patients. AJR Am J Roentgenol. 2002;179(1):75-80.

60. Zhang BH, Yang BH, Tang ZY. Randomized controlled trial of screening for hepatocellular carcinoma. J Cancer Res Clin Oncol. 2004;130(7): $417-422$.

61. Trevisani F, De NS, Rapaccini G, et al. Semiannual and annual surveillance of cirrhotic patients for hepatocellular carcinoma: effects on cancer stage and patient survival (Italian experience). Am J Gastroenterol. 2002;97(3):734-744.

62. Bolondi L, Sofia S, Siringo S, et al. Surveillance programme of cirrhotic patients for early diagnosis and treatment of hepatocellular carcinoma: a cost effectiveness analysis. Gut. 2001;48(2):251-259.

63. Davila JA, Morgan RO, Richardson PA, Du XL, McGlynn KA, El-Serag HB. Use of surveillance for hepatocellular carcinoma among patients with cirrhosis in the United States. Hepatology. 2010;52(1):132-141.

64. Gupta S, Bent S, Kohlwes J. Test characteristics of alpha-fetoprotein for detecting hepatocellular carcinoma in patients with hepatitis C. A systematic review and critical analysis. Ann Intern Med. 2003;139(1): 46-50.

65. Bruix J, Sherman M, Llovet JM, et al. EASL Panel of Experts on HCC. Clinical management of hepatocellular carcinoma. Conclusions of the Barcelona-2000 EASL conference. J Hepatol. 2001;35(3):421-430.

66. Sherman M. Serological surveillance for hepatocellular carcinoma: time to quit. $J$ Hepatol. 2010;52(4):614-615.

67. Marrero JA, El-Serag HB. Alpha-fetoprotein should be included in the hepatocellular carcinoma surveillance guidelines of the American Association for the Study of Liver Diseases. Hepatology. 2011;53(3):1060-1061; author reply 1061-1062.

68. Lok AS, Sterling RK, Everhart JE, et al. Des-gamma-carboxy prothrombin and alpha-fetoprotein as biomarkers for the early detection of hepatocellular carcinoma. Gastroenterology. 2010;138(2):493-502.

69. Marrero JA, Feng Z. Alpha-fetoprotein early hepatocellular carcinoma. Gastroenterology. 2010;138(1):400-401.

70. Marrero JA, Hussain HK, Nghiem HV, Umar R, Fontana RJ, Lok AS. Improving the prediction of hepatocellular carcinoma in cirrhotic patients with an arterially-enhancing liver mass. Liver Transpl. 2005;11(3):281-289.

71. Wilson SR, Burns PN. An algorithm for the diagnosis of focal liver masses using microbubble contrast-enhanced pulse-inversion sonography. AJR Am J Roentgenol. 2006;186(5):1401-1412. 
72. Lencioni R, Della Pina C, Crocetti L, Bozzi E, Cioni D. Clinical management of focal liver lesions: the key role of real-time contrastenhanced US. Eur Radiol. 2007;17 Suppl 6:F73-F79.

73. Strobel D, Seitz K, Blank W, et al. Tumor-specific vascularization pattern of liver metastasis, hepatocellular carcinoma, hemangioma and focal nodular hyperplasia in the differential diagnosis of 1,349 liver lesions in contrast-enhanced ultrasound (CEUS). Ultraschall Med. 2009;30(4):376-382.

74. von Herbay A, Westendorff J, Gregor M. Contrast-enhanced ultrasound with SonoVue: differentiation between benign and malignant focal liver lesions in 317 patients. J Clin Ultrasound. 2010;38(1):1-9.

75. Kim SH, Choi BI, Lee JY, et al. Diagnostic accuracy of multi-/ single-detector row CT and contrast-enhanced MRI in the detection of hepatocellular carcinomas meeting the Milan criteria before liver transplantation. Intervirology. 2008;51 Suppl 1:52-60.

76. Ariff B, Lloyd CR, Khan S, et al. Imaging of liver cancer. World J Gastroenterol. 2009;15(11):1289-1300.

77. Matsui O, Kadoya M, Kameyama T, et al. Benign and malignant nodules in cirrhotic livers: distinction based on blood supply. Radiology. 1991;178(2):493-497.

78. Ito K. Hepatocellular carcinoma: conventional MRI findings including gadolinium-enhanced dynamic imaging. Eur J Radiol. 2006;58(2):186-199.

79. Chanyaputhipong J, Low SC, Chow PK. Gadoxetate acid-enhancing MR imaging for HCC: a review for clinicians. Int J Hepatol. 2011;2011:489341.

80. Willatt JM, Hussain HK, Adusumilli S, Marrero JA. MR imaging of hepatocellular carcinoma in the cirrhotic liver: challenges and controversies. Radiology. 2008;247(2):311-330.

81. Burrel M, Llovet JM, Ayuso C, et al; Barcelona Clinic Liver Cancer Group. MRI angiography is superior to helical CT for detection of HCC prior to liver transplantation: an explant correlation. Hepatology. 2003;38(4):1034-1042.

82. Kim YK, Kim CS, Chung GH, et al. Comparison of gadobenate dimeglumine-enhanced dynamic MRI and 16-MDCT for the detection of hepatocellular carcinoma. AJR Am J Roentgenol. 2006;186(1):149-157.

83. Ebara M, Ohto M, Watanabe Y, et al. Diagnosis of small hepatocellular carcinoma: correlation of MR imaging and tumor histologic studies Radiology. 1986;159(2):371-377.

84. Krinsky GA, Lee VS, Theise ND, et al. Transplantation for hepatocellular carcinoma and cirrhosis: sensitivity of magnetic resonance imaging. Liver Transpl. 2002;8(12):1156-1164.

85. Kim JI, Lee JM, Choi JY, et al. The value of gadobenate dimeglumineenhanced delayed phase MR imaging for characterization of hepatocellular nodules in the cirrhotic liver. Invest Radiol. 2008;43(3):202-210.

86. Kim SH, Kim SH, Lee J, et al. Gadoxetic acid-enhanced MRI versus triple-phase MDCT for the preoperative detection of hepatocellular carcinoma. AJR Am J Roentgenol. 2009;192(6):1675-1681.

87. Okazumi S, Isono K, Enomoto K, et al. Evaluation of liver tumors using fluorine-18-fluorodeoxyglucose PET: characterization of tumor and assessment of effect of treatment. J Nucl Med. 1992;33(3):333-339.

88. Ho CL, Yu SC, Yeung DW. 11C-acetate PET imaging in hepatocellular carcinoma and other liver masses. J Nucl Med. 2003;44(2):213-221.

89. Park JW, Kim JH, Kim SK, et al. A prospective evaluation of 18F-FDG and $11 \mathrm{C}$-acetate PET/CT for detection of primary and metastatic hepatocellular carcinoma. J Nucl Med. 2008;49(12):1912-1921.

90. Forner A, Vilana R, Ayuso C, et al. Diagnosis of hepatic nodules $20 \mathrm{~mm}$ or smaller in cirrhosis: prospective validation of the noninvasive diagnostic criteria for hepatocellular carcinoma. Hepatology 2008;47(1):97-104.

91. Sangiovanni A, Manini MA, Iavarone M, et al. The diagnostic and economic impact of contrast imaging techniques in the diagnosis of small hepatocellular carcinoma in cirrhosis. Gut. 2010;59(5):638-644.

92. Silva MA, Hegab B, Hyde C, Guo B, Buckels JA, Mirza DF. Needle track seeding following biopsy of liver lesions in the diagnosis of hepatocellular cancer: a systematic review and meta-analysis. Gut. 2008;57(11):1592-1596.
93. International Consensus Group for Hepatocellular Neoplasia. Pathologic diagnosis of early hepatocellular carcinoma: a report of the international consensus group for hepatocellular neoplasia. Hepatology. 2009;49(2):658-664.

94. Llovet JM, Bru C, Bruix J. Prognosis of hepatocellular carcinoma: the BCLC staging classification. Semin Liver Dis. 1999;19(3):329-338.

95. Grieco A, Pompili M, Caminiti G, et al. Prognostic factors for survival in patients with early-intermediate hepatocellular carcinoma undergoing non-surgical therapy: comparison of Okuda, CLIP, and BCLC staging systems in a single Italian centre. Gut. 2005;54(3):411-418.

96. Marrero JA, Fontana RJ, Barrat A, et al. Prognosis of hepatocellular carcinoma: comparison of 7 staging systems in an American cohort. Hepatology. 2005;41(4):707-716.

97. Llovet JM, Fuster J, Bruix J. Intention-to-treat analysis of surgical treatment for early hepatocellular carcinoma: resection versus transplantation. Hepatology. 1999;30(6):1434-1440.

98. Forner A, Bruix J. East meets the West-portal pressure predicts outcome of surgical resection for hepatocellular carcinoma. Nat Clin Pract Gastroenterol Hepatol. 2009;6(1):14-15.

99. Ishizawa T, Hasegawa K, Aoki T, et al. Neither multiple tumors nor portal hypertension are surgical contraindications for hepatocellular carcinoma. Gastroenterology. 2008;134(7):1908-1916.

100. Balsells J, Charco R, Lazaro JL, et al. Resection of hepatocellular carcinoma in patients with cirrhosis. Br J Surg. 1996;83(6):758-761.

101. Breitenstein S, Apestegui C, Petrowsky H, Clavien PA. "State of the art" in liver resection and living donor liver transplantation: a worldwide survey of 100 liver centers. World J Surg. 2009;33(4):797-803.

102. Thakrar PD, Madoff DC. Preoperative portal vein embolization: an approach to improve the safety of major hepatic resection. Semin Roentgenol. 2011;46(2):142-153.

103. Poon RT, Fan ST, Wong J. Risk factors, prevention, and management of postoperative recurrence after resection of hepatocellular carcinoma. Ann Surg. 2000;232(1):10-24.

104. Poon RT. Prevention of recurrence after resection of hepatocellular carcinoma: a daunting challenge. Hepatology. 2011;54(3):757-759.

105. Sala M, Fuster J, Llovet JM, et al. High pathological risk of recurrence after surgical resection for hepatocellular carcinoma: an indication for salvage liver transplantation. Liver Transpl. 2004;10(10): 1294-1300.

106. Del Gaudio M, Ercolani G, Ravaioli M, et al. Liver transplantation for recurrent hepatocellular carcinoma on cirrhosis after liver resection: University of Bologna experience. Am J Transplant. 2008;8(6): 1177-1785.

107. Yoshida H, Shiratori Y, Kudo M, et al. Effect of vitamin K2 on the recurrence of hepatocellular carcinoma. Hepatology. 2011;54(2): $532-540$

108. Liu CJ, Lee PH, Lin DY, et al. Heparanase inhibitor PI-88 as adjuvant therapy for hepatocellular carcinoma after curative resection: a randomized phase II trial for safety and optimal dosage. $J$ Hepatol. 2009;50(5):958-968.

109. Mazzaferro V, Regalia E, Doci R, et al. Liver transplantation for the treatment of small hepatocellular carcinomas in patients with cirrhosis N Engl J Med. 1996;334(11):693-699.

110. Freeman RB, Wiesner RH, Edwards E, Harper A, Merion R, Wolfe R. Results of the first year of the new liver allocation plan. Liver Transpl. 2004;10(1):7-15.

111. Eguchi S, Hidaka M, Tomonaga T, et al. Actual therapeutic efficacy of pre-transplant treatment on hepatocellular carcinoma and its impact on survival after salvage living donor liver transplantation. J Gastroenterol. 2009;44(6):624-629.

112. Heckman J, Devera M, Marsh J, et al. Bridging locoregional therapy for hepatocellular carcinoma prior to liver transplantation. Ann Surg Oncol. 2008;15(11):3169-3177.

113. Cabrera R, Dhanasekaran R, Caridi J, et al. Impact of transarterial therapy in hepatitis C-related hepatocellular carcinoma on long-term outcomes after liver transplantation. Am J Clin Oncol. 2011. [Epub ahead of print.] 
114. Graziadei IW, Sandmueller H, Waldenberger P, etal. Chemoembolization followed by liver transplantation for hepatocellular carcinoma impedes tumor progression while on the waiting list and leads to excellent outcome. Liver Transpl. 2003;9(6):557-563.

115. Maddala YK, Stadheim L, Andrews JC, et al. Drop-out rates of patients with hepatocellular cancer listed for liver transplantation: outcome with chemoembolization. Liver Transpl. 2004;10(3):449-455.

116. Bruix J, Sherman M; American Association for the Study of Liver Diseases. Management of hepatocellular carcinoma: an update. Hepatology. 2011;53(3):1020-1022.

117. Yao FY, Hirose R, LaBerge JM, et al. A prospective study on downstaging of hepatocellular carcinoma prior to liver transplantation. Liver Transpl. 2005;11(12):1505-1514.

118. Vilana R, Bruix J, Bru C, Ayuso C, Sole M, Rodes J. Tumor size determines the efficacy of percutaneous ethanol injection for the treatment of small hepatocellular carcinoma. Hepatology. 1992;16(2):353-357.

119. Lencioni R, Crocetti L. A critical appraisal of the literature on local ablative therapies for hepatocellular carcinoma. Clin Liver Dis. 2005;9(2):301-314.

120. Bouza C,Lopez-CuadradoT,AlcazarR, Saz-ParkinsonZ, Amate J. Metaanalysis of percutaneous radiofrequency ablation versus ethanol injection in hepatocellular carcinoma. BMC Gastroenterol. 2009;9:31.

121. Lencioni RA, Allgaier HP, Cioni D, et al. Small hepatocellular carcinoma in cirrhosis: randomized comparison of radio-frequency thermal ablation versus percutaneous ethanol injection. Radiology. 2003;228(1):235-240.

122. Liang P, Wang Y. Microwave ablation of hepatocellular carcinoma. Oncology. 2007;72 Suppl 1:124-131.

123. Davalos RV, Mir IL, Rubinsky B. Tissue ablation with irreversible electroporation. Ann Biomed Eng. 2005;33(2):223-231.

124. Angiodynamics Inc. Pilot study of irreversible electroporation (IRE) to treat early-stage primary liver cancer (HCC). In: ClinicalTrials. gov [Internet]. Bethesda, MD: National Library of Medicine (US). February 26, 2010 [last updated September 26, 2011]. Available from: http://clinicaltrials.gov/ct2/show/NCT01078415. NLM identifier: NCT01078415.

125. Celsion. A study of ThermoDox ${ }^{\mathrm{TM}}$ in combination with radiofrequency ablation (RFA) in primary and metastatic tumors of the liver. In: ClinicalTrials.gov [Internet]. Bethesda, MD: National Library of Medicine (US). February 26, 2007 [last updated December 16, 2009]. Available from: http://clinicaltrials.gov/ct2/show/NCT00441376. NLM identifier: NCT00441376.

126. Llovet JM, Real MI, Montana X, et al. Arterial embolisation or chemoembolisation versus symptomatic treatment in patients with unresectable hepatocellular carcinoma: a randomised controlled trial. Lancet. 2002;359(9319):1734-1739.

127. Lo CM, Ngan H, Tso WK, et al. Randomized controlled trial of trans-arterial lipiodol chemoembolization for unresectable hepatocellular carcinoma. Hepatology. 2002;35(5):1164-1171.

128. Llovet JM, Bruix J. Systematic review of randomized trials for unresectable hepatocellular carcinoma: chemoembolization improves survival. Hepatology. 2003;37(2):429-442.

129. Georgiades CS, Hong K, D’Angelo M, Geschwind JF. Safety and efficacy of transarterial chemoembolization in patients with unresectable hepatocellular carcinoma and portal vein thrombosis. J Vasc Interv Radiol. 2005;16(12):1653-1659.

130. Raoul JL, Heresbach D, Bretagne JF, et al. Chemoembolization of hepatocellular carcinomas. A study of the biodistribution and pharmacokinetics of doxorubicin. Cancer. 1992;70(3):585-590.

131. Sakamoto I, Aso N, Nagaoki K, et al. Complications associated with transcatheter arterial embolization for hepatic tumors. Radiographics. 1998;18(3):605-619.

132. Lencioni R. Loco-regional treatment of hepatocellular carcinoma. Hepatology. 2010;52(2):762-773.

133. Varela M, Real MI, Burrel M, et al. Chemoembolization of hepatocellular carcinoma with drug eluting beads: efficacy and doxorubicin pharmacokinetics. J Hepatol. 2007;46(3):474-481.
134. Poon RT, Tso WK, Pang RW, et al. A phase I/II trial of chemoembolization for hepatocellular carcinoma using a novel intraarterial drug-eluting bead. Clin Gastroenterol Hepatol. 2007;5(9): 1100-1108.

135. Lammer J, Malagari K, Vogl T, et al. Prospective randomized study of doxorubicin-eluting-bead embolization in the treatment of hepatocellular carcinoma: results of the PRECISION V study. Cardiovasc Intervent Radiol. 2010;33(1):41-52.

136. Bilbao JI, de Luis E, Garcia de Jalon JA, et al. Comparative study of four different spherical embolic particles in an animal model: a morphologic and histologic evaluation. JVasc Interv Radiol. 2008;19(11): 1625-1638.

137. Kulik LM, Atassi B, van Holsbeeck L, et al. Yttrium-90 microspheres (TheraSphere) treatment of unresectable hepatocellular carcinoma: downstaging to resection, RFA and bridge to transplantation. J Surg Oncol. 2006;94(7):572-586.

138. Salem R, Lewandowski RJ, Mulcahy MF, et al. Radioembolization for hepatocellular carcinoma using Yttrium-90 microspheres: a comprehensive report of long-term outcomes. Gastroenterology. 2010; 138(1):52-64

139. Sangro B, Carpanese L, Cianni R, et al; European Network on Radioembolization with Yttrium-90 Resin Microspheres. Survival after yttrium-90 resin microsphere radioembolization of hepatocellular carcinoma across Barcelona Clinic Liver Cancer stages: a European evaluation. Hepatology. 2011;54(3):868-878.

140. Salem R, Lewandowski RJ, Kulik L, et al. Radioembolization results in longer time-to-progression and reduced toxicity compared with chemoembolization in patients with hepatocellular carcinoma. Gastroenterology. 2011;140(2):497-507.

141. Li X, Feng GS, Zheng CS, Zhuo CK, Liu X. Expression of plasma vascular endothelial growth factor in patients with hepatocellular carcinoma and effect of transcatheter arterial chemoembolization therapy on plasma vascular endothelial growth factor level. World J Gastroenterol. 2004;10(19):2878-2882.

142. Dufour JF, Hoppe H, Heim MH, et al. Continuous administration of sorafenib in combination with transarterial chemoembolization in patients with hepatocellular carcinoma: results of a phase I study. Oncologist. 2010;15(11):1198-1204.

143. Cabrera R, Pannu D, Caridi J, et al. The combination of sorafenib with transarterial chemoembolization for hepatocellular carcinoma. Aliment Pharmacol Ther. 2011;34(2):205-213.

144. Llovet JM, Ricci S, Mazzaferro V, et al. Sorafenib in advanced hepatocellular carcinoma. N Engl J Med. 2008;359(4):378-390.

145. Cheng AL, Kang YK, Chen Z, et al. Efficacy and safety of sorafenib in patients in the Asia-Pacific region with advanced hepatocellular carcinoma: a phase III randomised, double-blind, placebo-controlled trial. Lancet Oncol. 2009;10(1):25-34.

146. Park JW, Finn RS, Kim JS, et al. Phase II, open-label study of brivanib as first-line therapy in patients with advanced hepatocellular carcinoma. Clin Cancer Res. 2011;17(7):1973-1983.

147. Bristol-Myers Squibb. First line hepato cellular carcinoma (HCC) (BRISK FL). In: ClinicalTrials.gov [Internet]. Bethesda, MD: National Library of Medicine (US). March 9, 2009 [last updated February 15, 2012]. Available from: http://clinicaltrials.gov/ct2/show/ NCT00858871. NLM identifier: NCT00858871.

148. Bristol-Myers Squibb. Comparison of brivanib and best supportive care to placebo for treatment of liver cancer for those subjects who have failed sorafenib treatment (BRISK PS). In: ClinicalTrials. gov [Internet]. Bethesda, MD: National Library of Medicine (US). January 20, 2009 [last updated February 15, 2012]. Available from: http:/clinicaltrials.gov/ct2/show/NCT00825955. NLM identifier: NCT00825955.

149. Bristol-Myers Squibb. Phase III trans-arterial chemo-embolization (TACE) adjuvant HCC (BRISK TA). In: ClinicalTrials.gov [Internet]. Bethesda, MD: National Library of Medicine (US). May 22, 2009 [last updated February 21, 2012]. Available from: http://clinicaltrials.gov/ ct2/show/NCT00908752. NLM identifier: NCT00908752. 
150. Abou-Alfa GK, Johnson P, Knox JJ, et al. Doxorubicin plus sorafenib vs doxorubicin alone in patients with advanced hepatocellular carcinoma: a randomized trial. JAMA. 2010;304(19):2154-2160.

151. University of Florida. Sorafenib dose ramp-up in hepatocellular carcinoma (HCC). In: ClinicalTrials.gov [Internet]. Bethesda, MD: National Library of Medicine (US). September 10, 2010 [last updated October 11, 2011]. Available from: http://www.clinicaltrials.gov/ ct2/show/NCT01203787. NLM identifier: NCT01203787. Accessed August 23, 2011.

152. Philip PA, Mahoney MR, Allmer C, et al. Phase II study of erlotinib (OSI-774) in patients with advanced hepatocellular cancer. J Clin Oncol. 2005;23(27):6657-6663.

153. Thomas MB, Morris JS, Chadha R, et al. Phase II trial of the combination of bevacizumab and erlotinib in patients who have advanced hepatocellular carcinoma. J Clin Oncol. 2009;27(6):843-850.

154. Medical University of South Carolina. Bevacizumab and erlotinib or sorafenib as first-line therapy in treating patients with advanced liver cancer. In: ClinicalTrials.gov [Internet]. Bethesda, MD: National Library of Medicine (US). April 14, 2009 [last updated January 24, 2012]. Available from: http://clinicaltrials.gov/ct2/show/ NCT00881751. NLM identifier: NCT00881751.

155. MD Anderson Cancer Center; Genentech and OSI Pharmaceuticals. Erlotinib plus bevacizumab in hepatocellular carcinoma (HCC) as second-line therapy. In: ClinicalTrials.gov [Internet]. Bethesda, MD: National Library of Medicine (US). August 11, 2010 [last updated January 17, 2012]. Available from: http://clinicaltrials.gov/ct2/show/ NCT01180959. NLM identifier: NCT01180959.

156. Ramanathan RK, Belani CP, Singh DA, et al. A phase II study of lapatinib in patients with advanced biliary tree and hepatocellular cancer. Cancer Chemother Pharmacol. 2009;64(4):777-783.

157. Bekaii-Saab T, Markowitz J, Prescott N, et al. A multi-institutional phase II study of the efficacy and tolerability of lapatinib in patients with advanced hepatocellular carcinomas. Clin Cancer Res. 2009; 15(18):5895-5901.

158. O’Dwyer PJ, Giantonio BJ, Levy DE, Kauh JS, Fitzgerald DB, Benson AB. Gefitinib in advanced unresectable hepatocellular carcinoma: results from the Eastern Cooperative Oncology Group's Study E1203 [abstract]. J Clin Oncol. 2006;24(Suppl 18):4143.
159. Zhu AX, Stuart K, Blaszkowsky LS, et al. Phase 2 study of cetuximab in patients with advanced hepatocellular carcinoma. Cancer. 2007;110(3):581-589.

160. Asnacios A, Fartoux L, Romano O, et al. Gemcitabine plus oxaliplatin (GEMOX) combined with cetuximab in patients with progressive advanced stage hepatocellular carcinoma: results of a multicenter phase 2 study. Cancer. 2008;112(12):2733-2739.

161. Jasinghe VJ, Xie Z, Zhou J, et al. ABT-869, a multi-targeted tyrosine kinase inhibitor, in combination with rapamycin is effective for subcutaneous hepatocellular carcinoma xenograft. $J$ Hepatol. 2008;49(6):985-997.

162. O'Neil BH, Williams-Goff LW, Kauh J, et al. A phase II study of AZD6244 in advanced or metastatic hepatocellular carcinoma [abstract]. J Clin Oncol. 2009;Suppl 27:e15574.

163. Sun W, Nelson D, Alberts SR, et al. Phase Ib study of mapatumumab in combination with sorafenib in patients with advanced hepatocellular carcinoma (HCC) and chronic viral hepatitis [abstract]. J Clin Oncol. 2011;29(Suppl 4):261.

164. Chen L, Shiah HS, Chen CY, et al. Randomized, phase I, and pharmacokinetic (PK) study of RAD001, an mTOR inhibitor, in patients (pts) with advanced hepatocellular carcinoma (HCC) [abstract]. J Clin Oncol. 2009;27(15 Suppl):4587.

165. Blaszkowsky LS, Abrams TA, Miksad RA, et al. Phase I/II study of everolimus in patients with advanced hepatocellular carcinoma (HCC) [abstract]. J Clin Oncol. 2010;Suppl 28:e14542.

166. Zhu AX, Finn RS, Mulcahy MF, et al. A phase II study of ramucirumab as first-line monotherapy in patients (pts) with advanced hepatocellular carcinoma (HCC) [abstract]. J Clin Oncol. 2010;28(15 Suppl):4083.

167. Raoul JL, Finn RS, Kang YK, et al. An open-label phase II study of first- and second-line treatment with brivanib in patients with hepatocellular carcinoma (HCC) [abstract]. J Clin Oncol. 2009; 27(Suppl 15):4577.

168. Bristol-Myers Squibb. BRISK-PS study with investigational compound brivanib in hepatocellular carcinoma completed [press release]. In: Yahoo! Finance [website on the Internet]. December 22, 2011. Available from: http://finance.yahoo.com/news/BRISK-PS-Studybw-2323246800.html?x=0. Accessed February 9, 2012
Hepatic Medicine: Evidence and Research

\section{Publish your work in this journal}

Hepatic Medicine: Evidence and Research is an international, peerreviewed, open access journal covering all aspects of adult and pediatric hepatology in the clinic and laboratory including the following topics: Pathology, pathophysiology of hepatic disease; Investigation and treatment of hepatic disease; Pharmacology of drugs used for

\section{Dovepress}

the treatment of hepatic disease. Issues of patient safety and quality of care will also be considered. The manuscript management system is completely online and includes a very quick and fair peer-review system, which is all easy to use. Visit http://www.dovepress.com/ testimonials.php to read real quotes from published authors. 